This article has been scanned by iThenticat No plagiarism detected

Volume 3, Issue 3, June 2021

p. $134-147$

\title{
THE PIONEERING ROLE OF SHARIA SCHOLARS IN THE CORONA PANDEMIC
}

\author{
http://dx.doi.org/10.47832/2757-5403.3-3.13
}

Najwa N. A. SHKOKANI 1

\begin{abstract}
:
The majority of societies on Earth suffered a lot physically, psychologically, intellectually and financially during the Corona Covid19 epidemic in the period 2020-2021, which surprised everyone with the speed and severity of its spread and lethality all over the world, and with the severity of the preventive measures that forced people to adhere to it. Despite all the crises that accompanied it or resulted from it, the scholars of Sharia, despite their great efforts in the field of fatwas that have taken place, nevertheless the common Muslims felt their lack of a pioneering and effective role for them, for they are the scholars of the ummah. And their deeds rise to the level appropriate to the greatness of Islam and lead it to serve mankind in all circumstances, in all societies and at all times. So did they take advantage of the circumstances and in the jurisprudence councils, legal universities, Islamic think tanks and others, hastened to meet and consult periodically and intensely commensurate with the momentum of the developments that took place in that event and the pursuit of the event in all its aspects and dynamics, and has the effect of this appeared in several aspects in Islamic societies and elsewhere? The Holy Qur'an and
\end{abstract} the Noble Prophet's Sunnah have revealed this pioneering role by the prophets and messengers, saints and scholars. Scholars of true law at all times are the heirs of the prophets, and enjoining good and forbidding evil depends on their guidance and diligence. Likewise, that role is not hidden in the wonderful models launched in Islamic societies throughout its prosperous history in all aspects of life, and in all the circumstances and conditions that it has gone through, including calamities, tribulations, misfortunes, strife, diseases and epidemics, which had the greatest positive impact on the Ummah's awareness and knowledge of good behavior in it. To prevent the largest proportion of the losses in the lives of people and the good of the country. This study comes by following the descriptive and analytical method to highlight the aforementioned by introducing the Corona epidemic, and the inductive approach by exploring the pioneering role of true Islamic law scholars in epidemics by referring to the sources of legislation with evidence of that throughout Islamic history, then searching for that application in this era, following the field approach Al-Estebyani, with

\footnotetext{
${ }^{1}$ Dr. , Palestine, najuanaief2015@gmail.com, https://orcid.org/0000-0003-1497-188X
} 
investigating their positions during that epidemic. The most prominent results after the research were: That Islamic scholars have the greatest importance that goes beyond the intellectuals, thinkers, and even politicians, and they are at the forefront of society in researching and uncovering how to deal with epidemics according to Sharia evidence, using all means and techniques, both ancient and modern. And adopting educational, informational and advocacy methods in generalizing how people deal with the epidemic; And to highlight the faith role that achieves security, tranquility, and satisfaction with the judgment of God, adhering to the teachings of Islam in that event and responding to the responsible represented by the intellectual, political, health and other systems, and they also have a great impact on societies when they rush to issue fatwas to guide individuals and governments in how to deal with this pandemic, and not to stop Then, it is imperative to constantly and diligently follow up on the developments of the epidemic with the permanent meeting of fatwa councils locally and internationally, in order to change the fatwas and procedures in line with the new circumstances. That Muslim scholars have been the pioneering and guiding reed throughout history represented by models that elevated themselves, their nation, and humanity as well.

Key words: Pioneering Role, Epidemic, Pandemic, Corona Covid 19, Forensic Scholars.

\section{الاور الريادي لعلماء الثرع في جائحة كورونا}

\section{نجوى نايف شكوكاني 2}

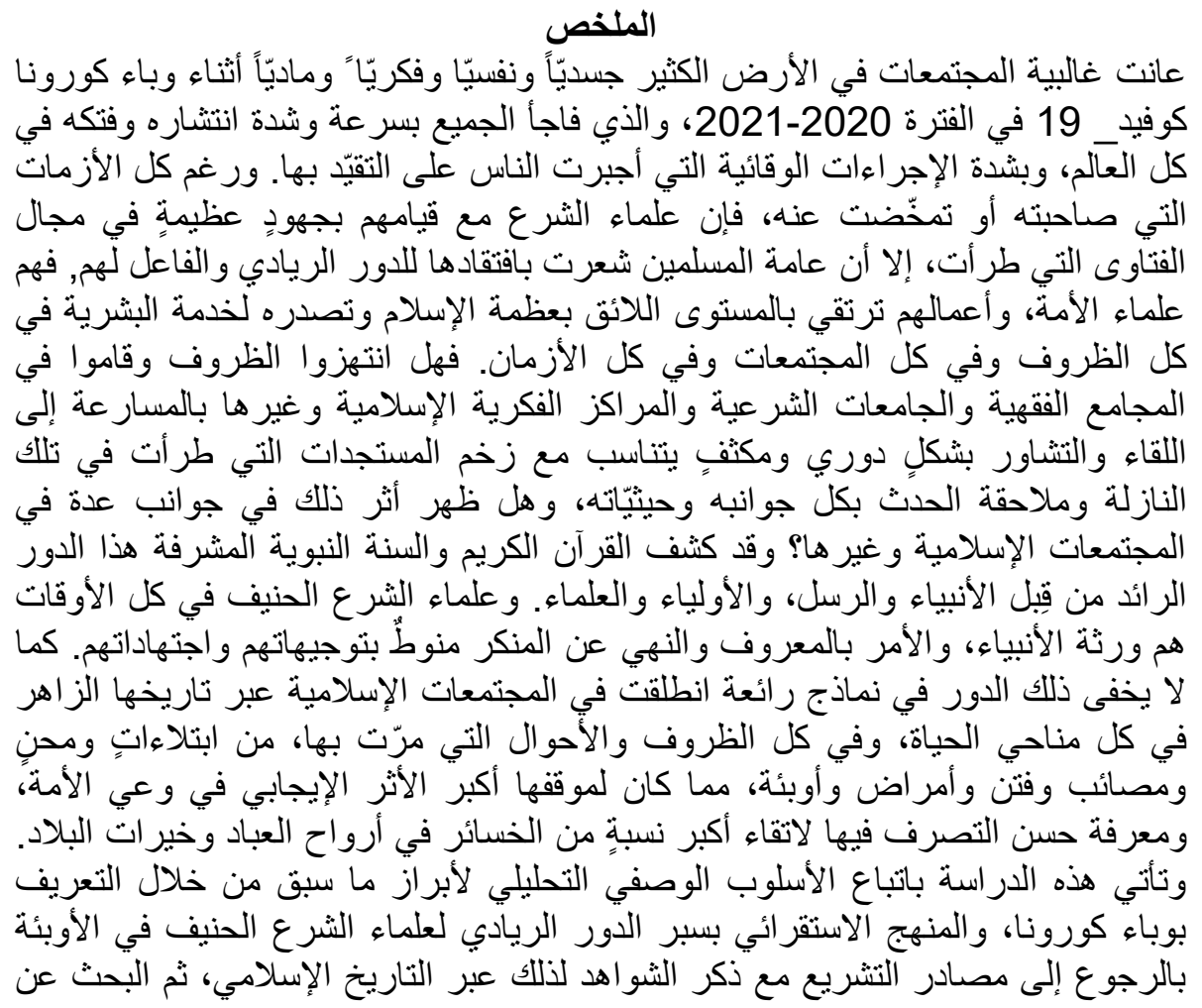

2. د.، قسم التعليم والتأهيل في مديرية الأوقاف في القد، فلسطين، najuanaief2015@gmail.com 


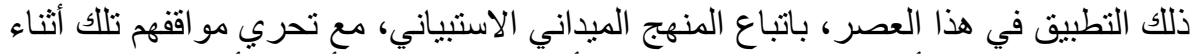

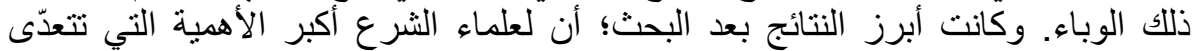

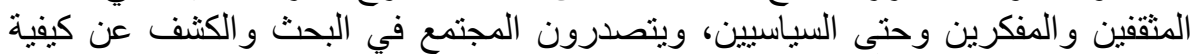

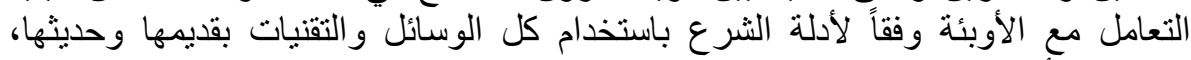

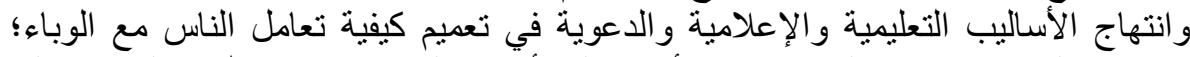

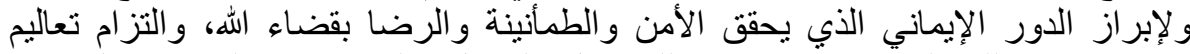

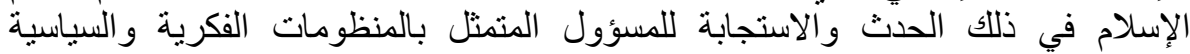

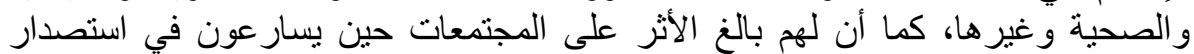

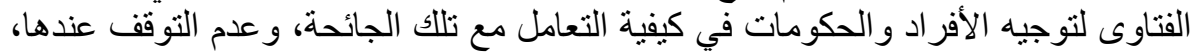

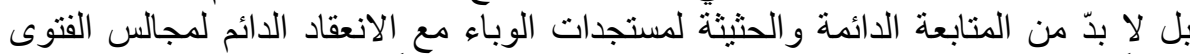

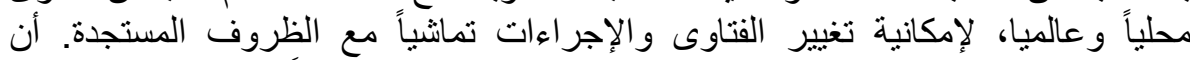

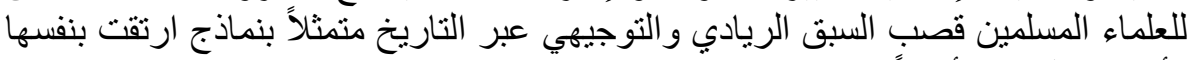

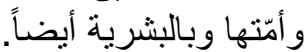

الكلمات المفتاحية: دور ريادي، ألنية وباء، جائحة، كورونا كوفيد 19، علماء الثرع.

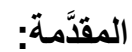

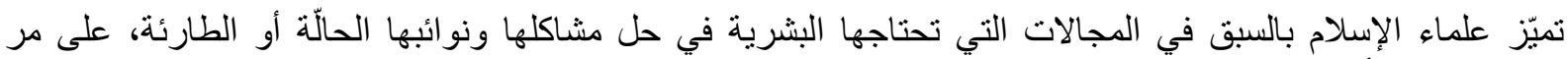

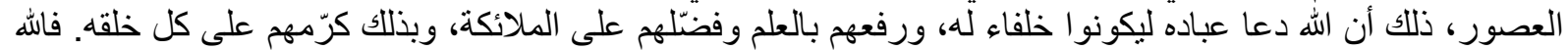

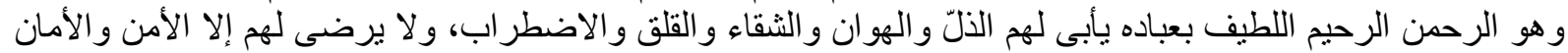

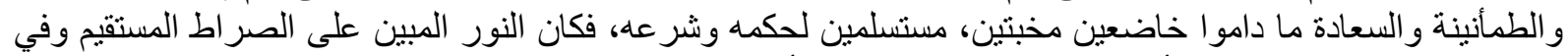

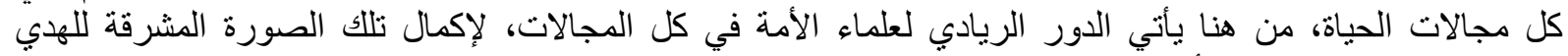
الرباني للبشرية و على مرّ الأزمان. يدور هذا البحث حول الدور الريّادي الازمان لعلماء الثرع في جائحة كورونا، والمشكلة فيه هي معرفة ذلك الدور الريادي

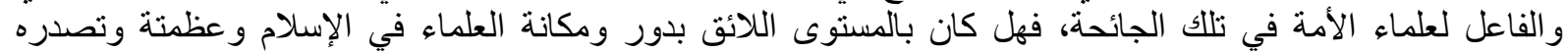

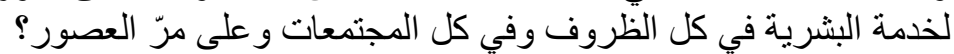

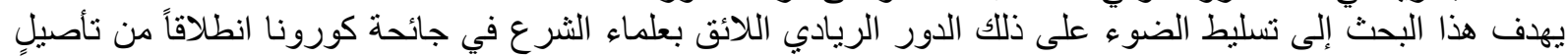

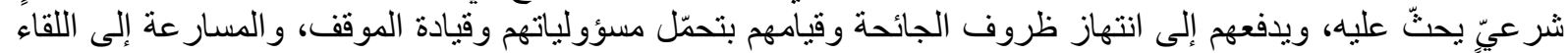

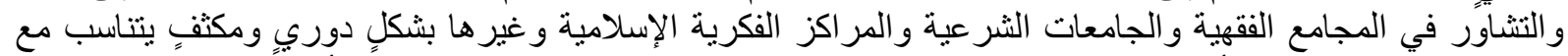

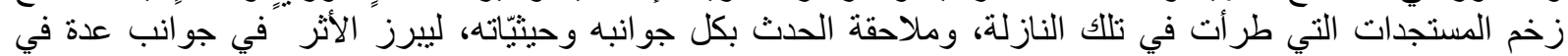

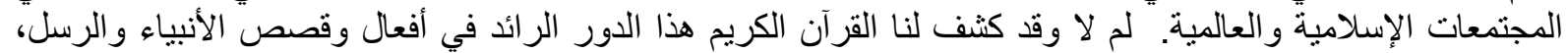

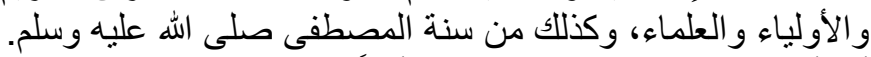

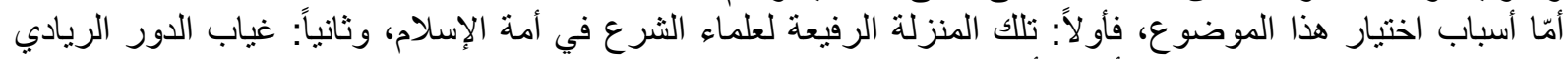

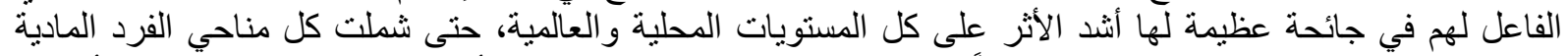

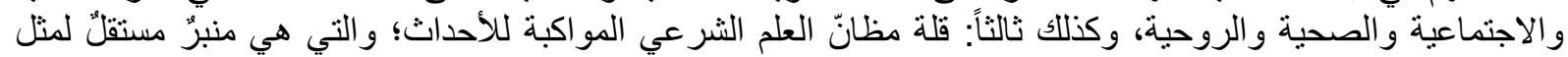

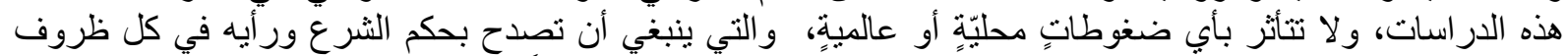

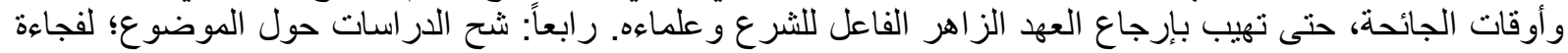

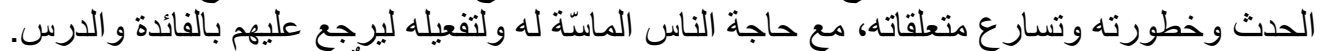

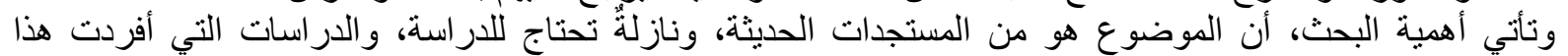

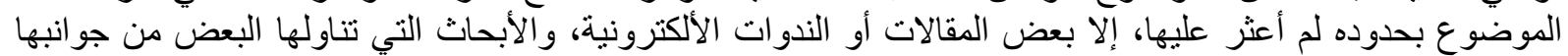

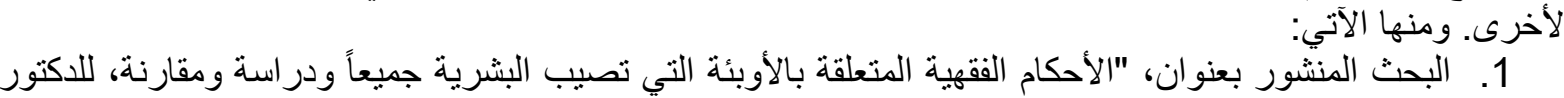

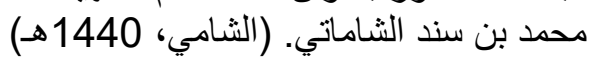

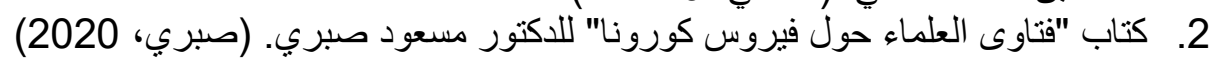

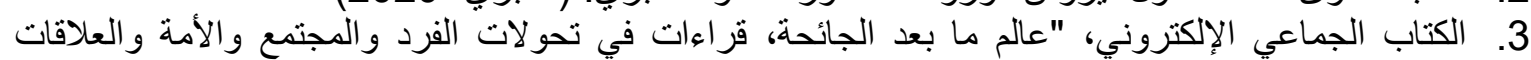
الدولية. (البنعيادي، شعايب، الإكترون، آخرون، مل بعد 2020م) 


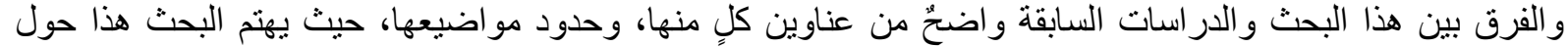

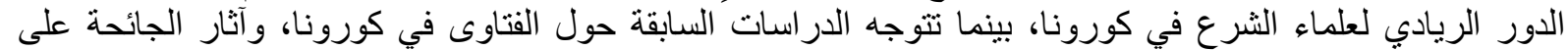

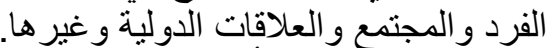

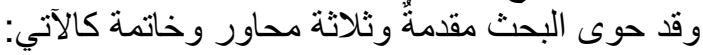

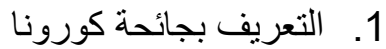

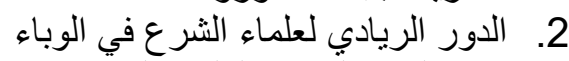

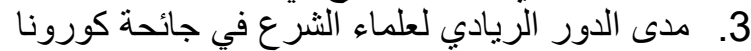

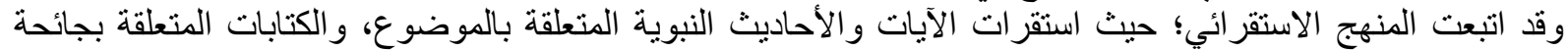

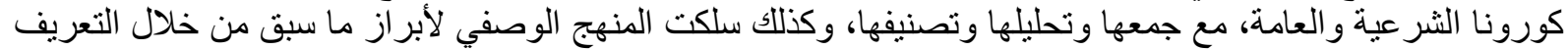

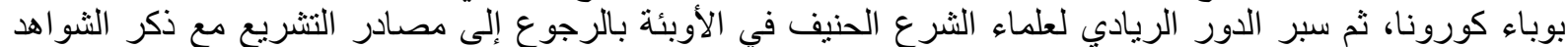

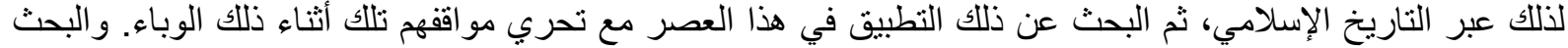

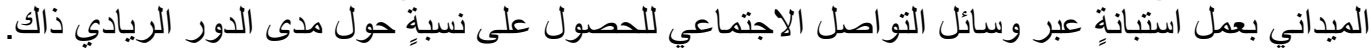

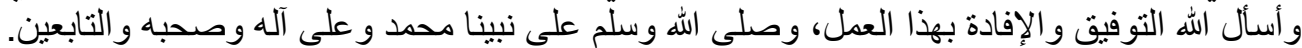
التعريف بجائحة كورونا:

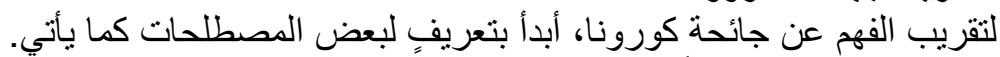

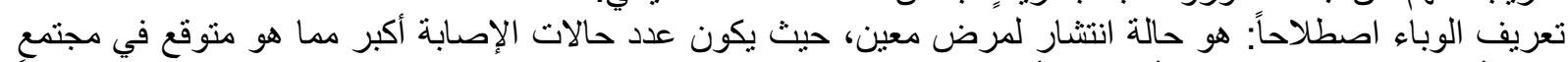

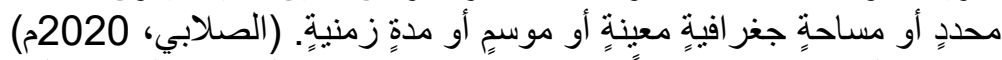

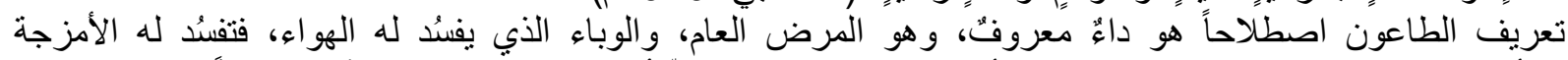

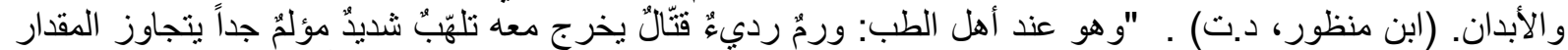

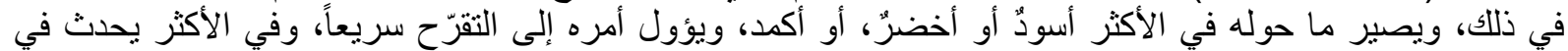

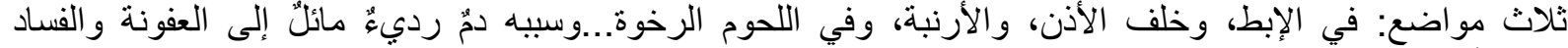

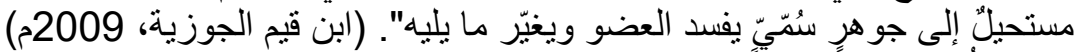

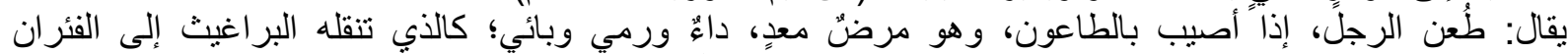

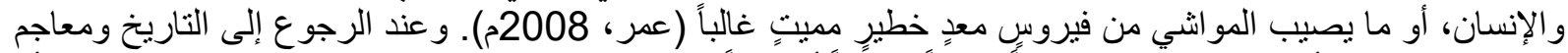

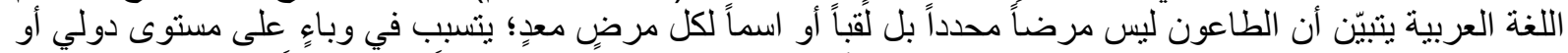

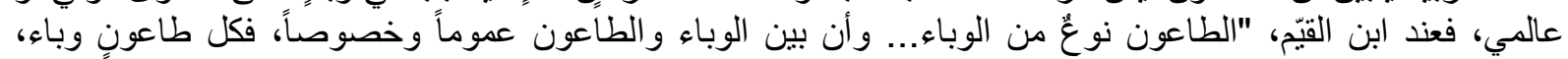

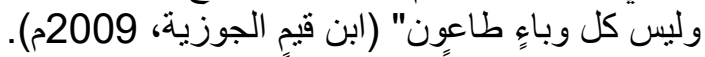

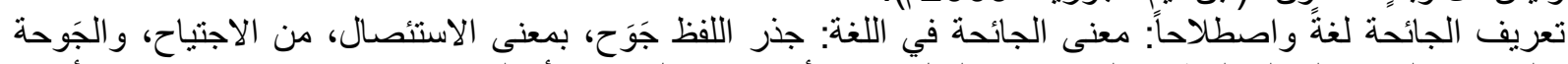

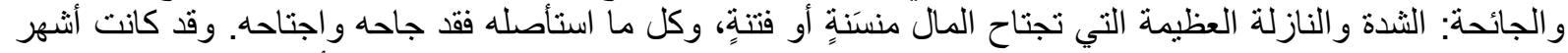

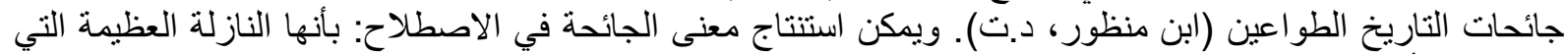

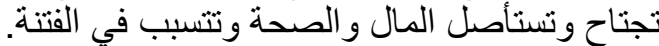

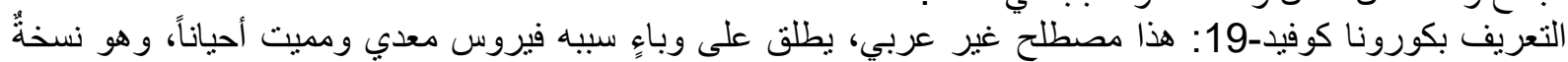

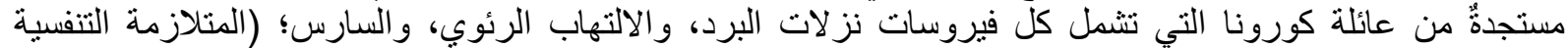

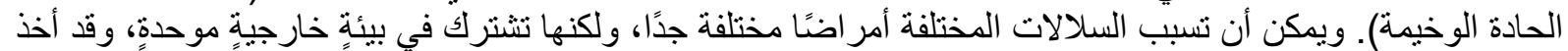

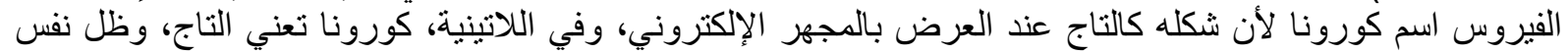

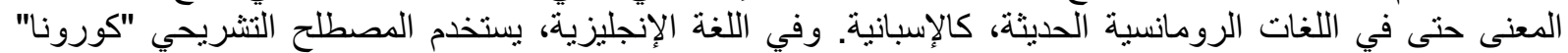

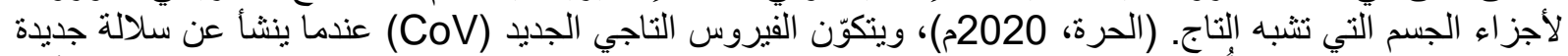

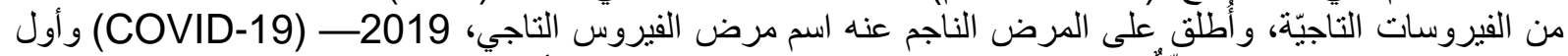

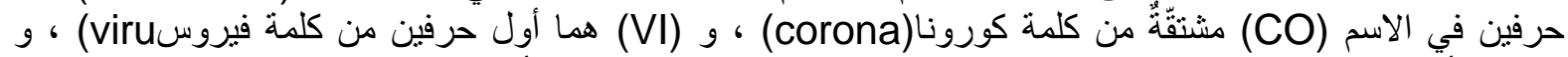
(D) أول حرف من كلمة مرض بالإنجليزية(disease) وقد كان ظهر لأول مرة في بلدة (ووهان) بالصين (لكل

طفل، 2020)

الدور الريادي لعلماء الثرع في الوياء:

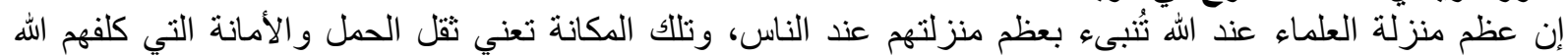

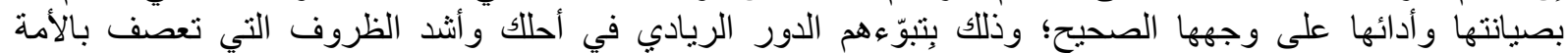

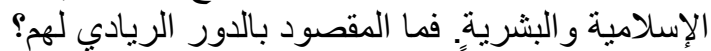

تعريف الريادي لغة والئة واصطلاحاً

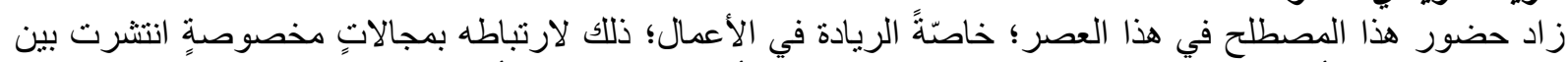

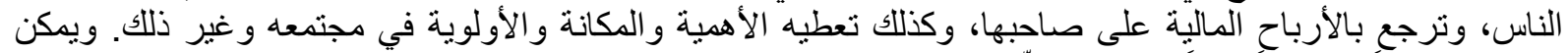

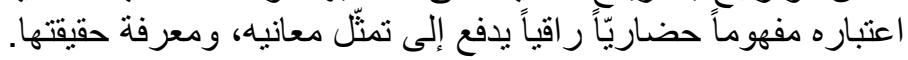




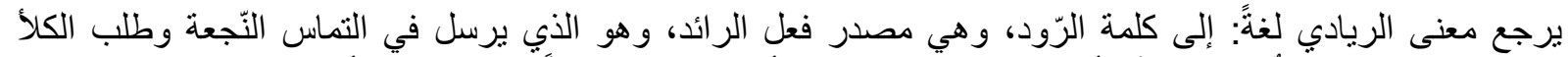

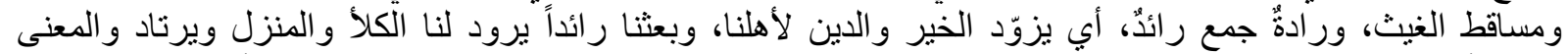

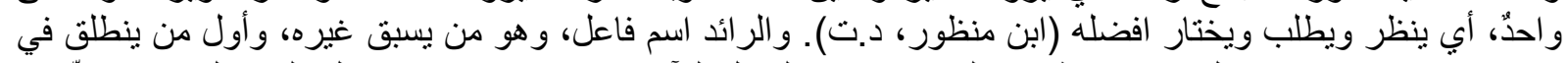

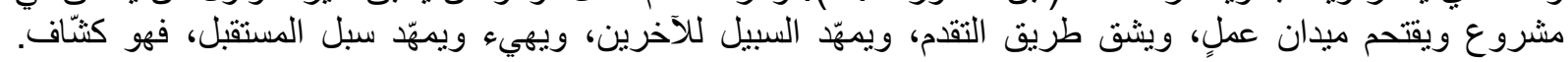

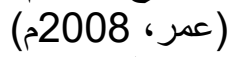

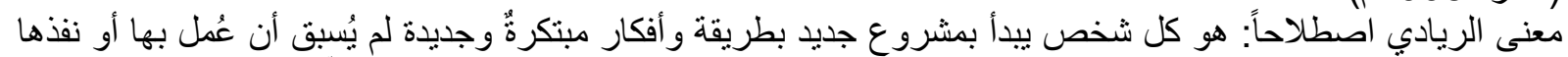

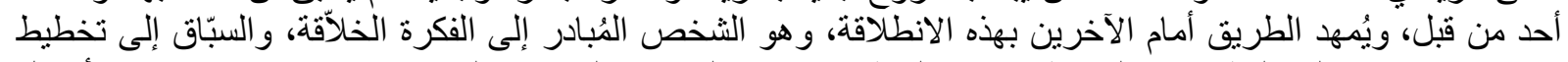

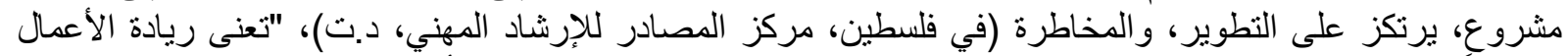

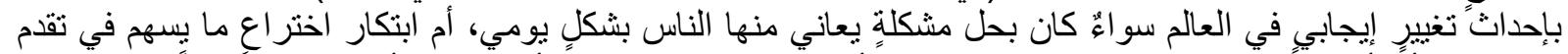

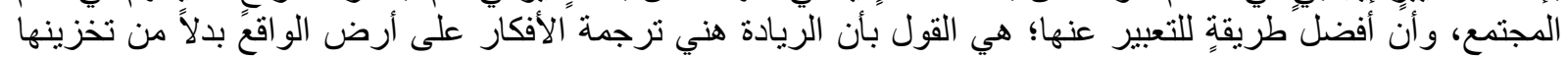

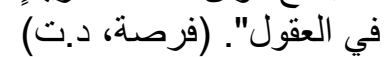

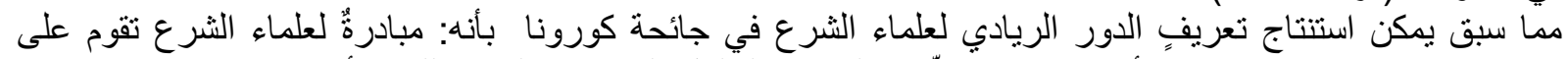

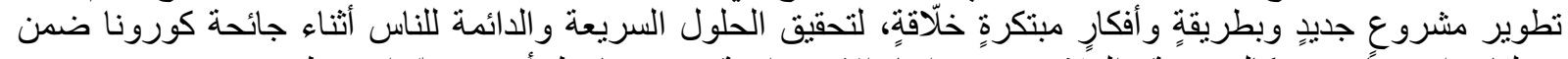

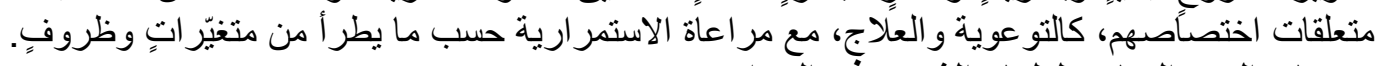

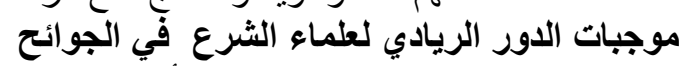

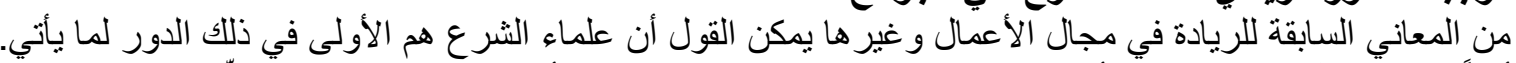

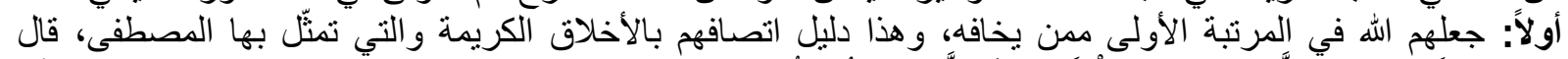

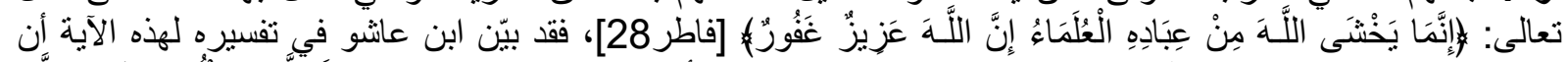

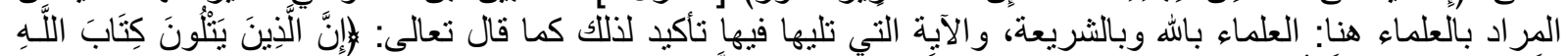

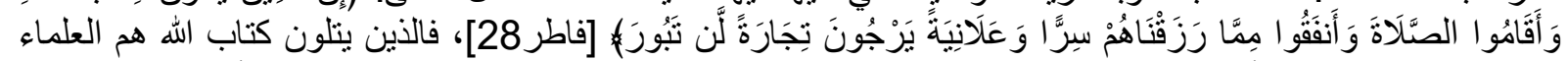

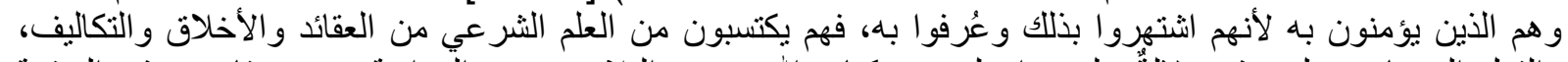

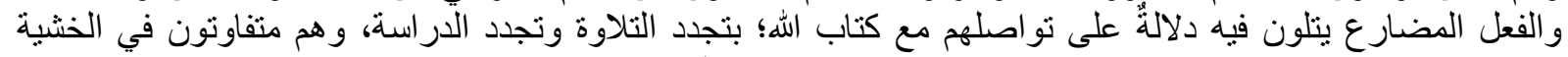

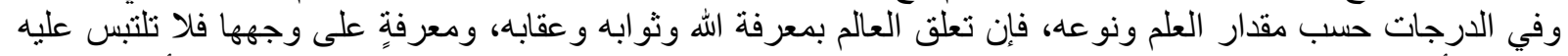

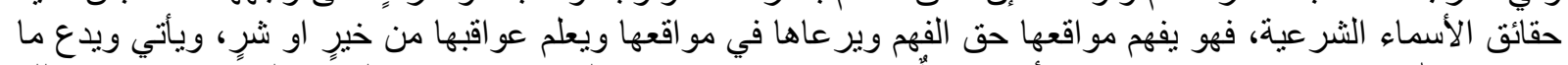

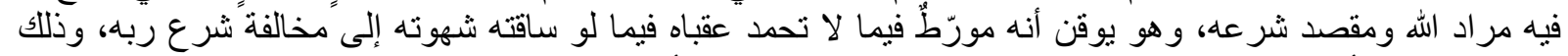

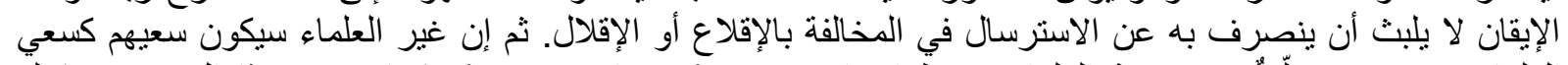

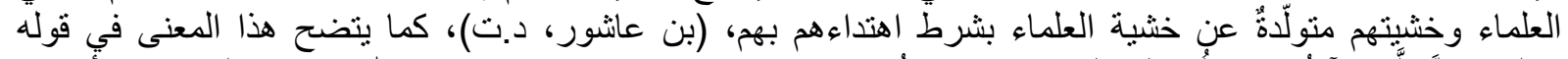

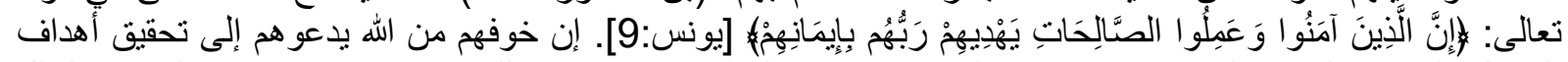

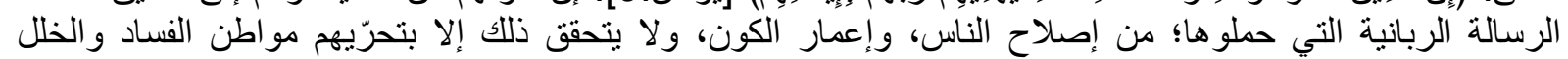

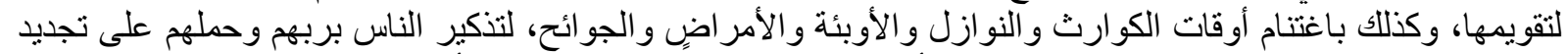

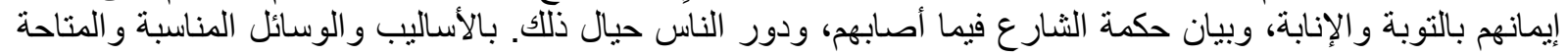

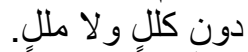

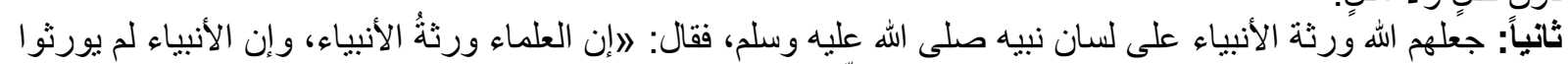

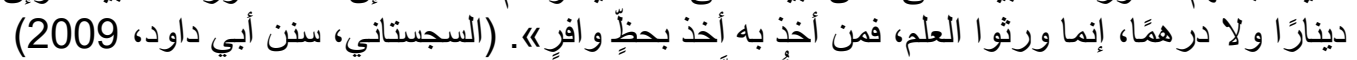

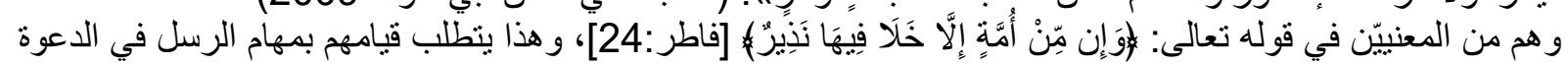

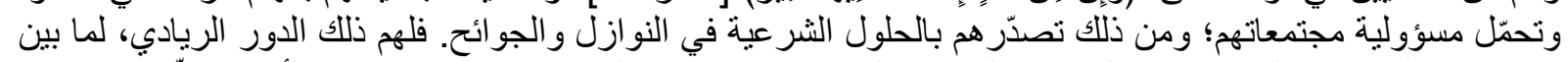

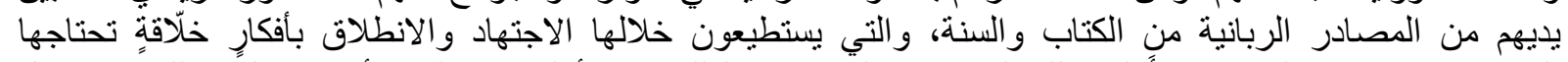

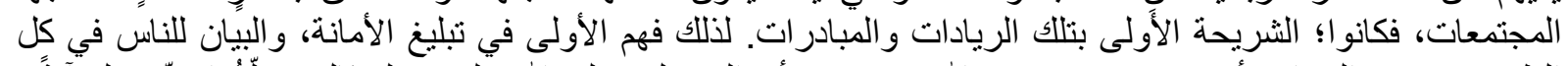

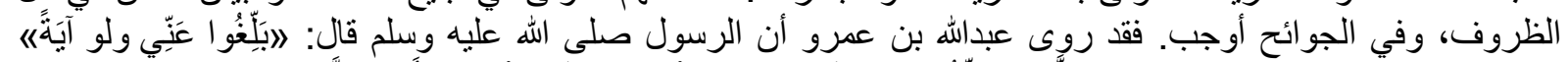

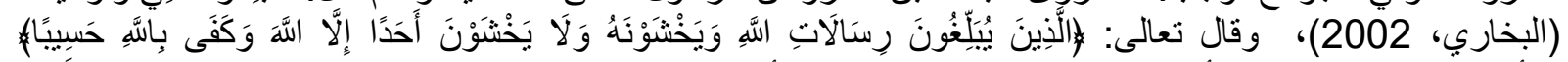

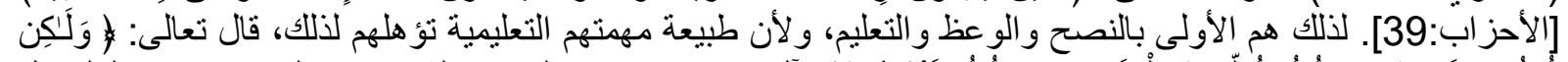

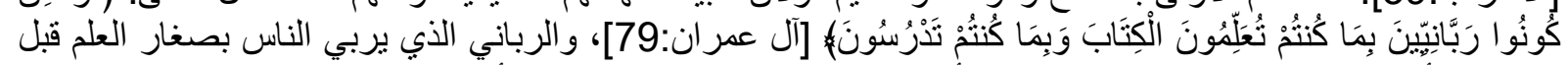

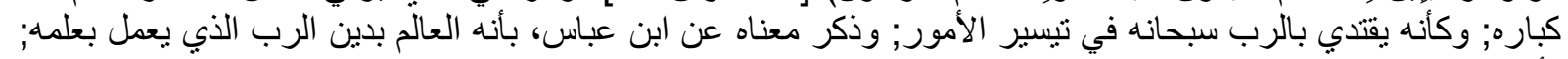

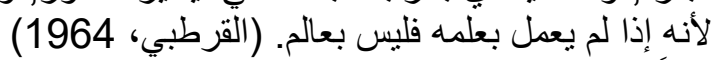

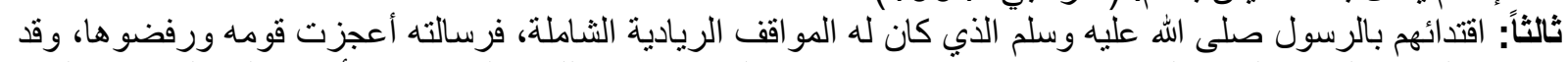

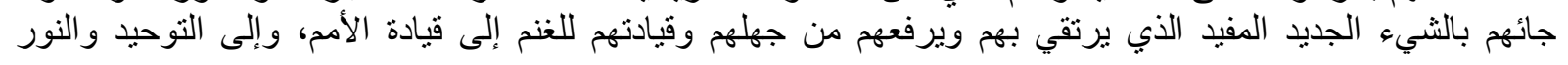


بتحرير هم من الوثثية، ورفعهم إلى مكانتهم بدل إهانة النفس وذلّها واستعبادها للحيوان و الحجر و الوثن و الثيطان، فكانت

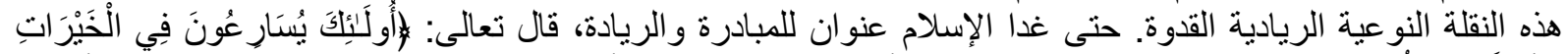

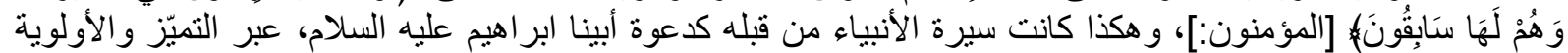

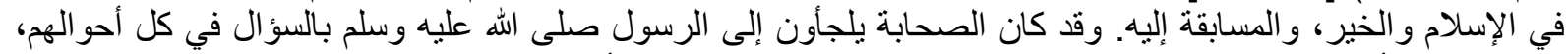

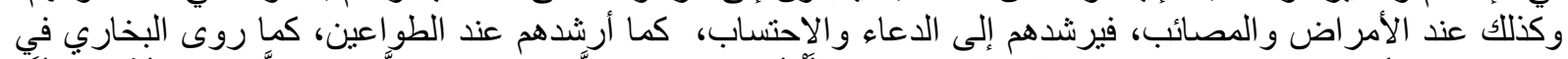

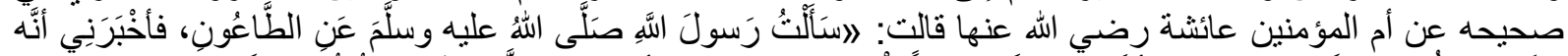

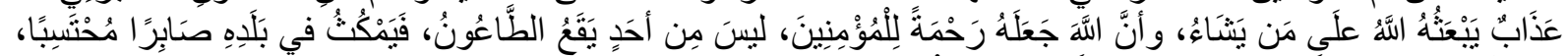

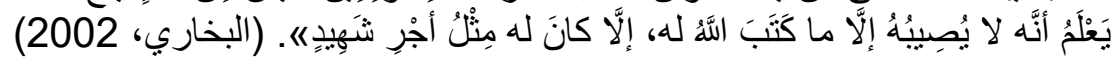

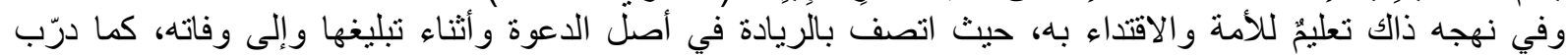

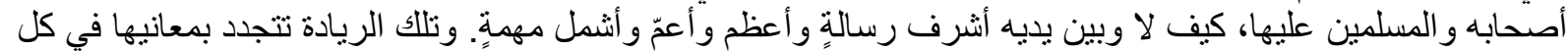

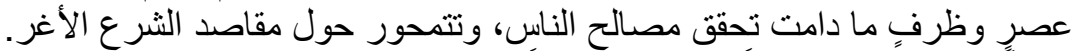

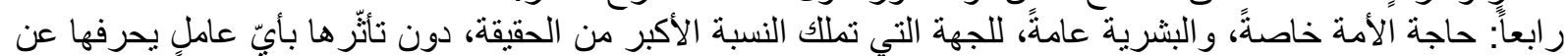

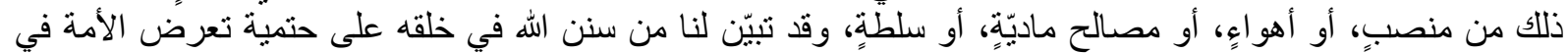

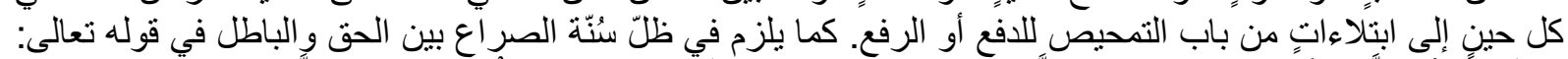

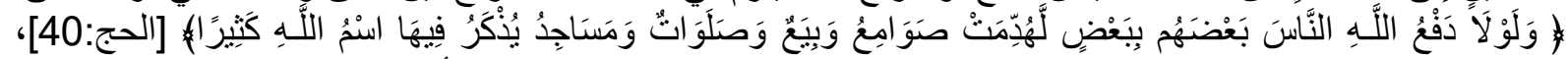

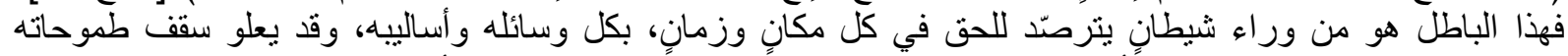

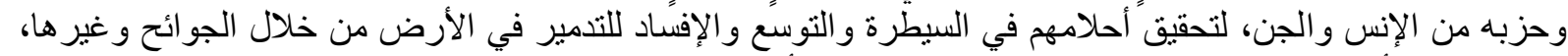

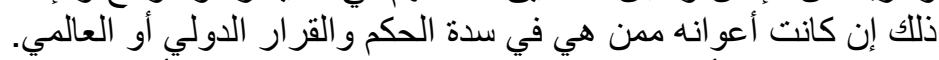

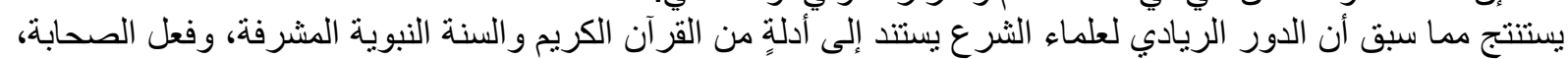

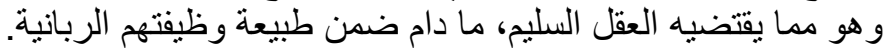
دور علماء الثرع أثناء الأوبئة

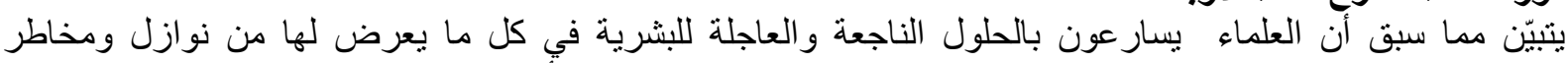

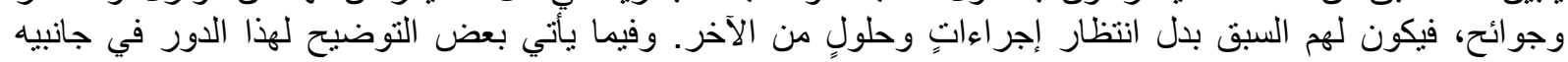
النظري و العملي. التوعيةٌ والتوجيه

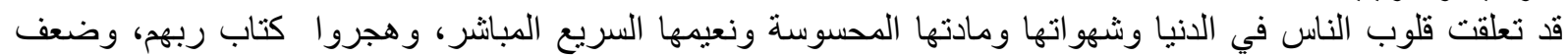

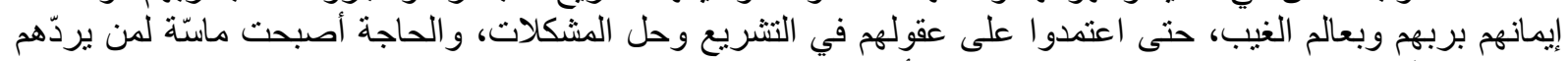

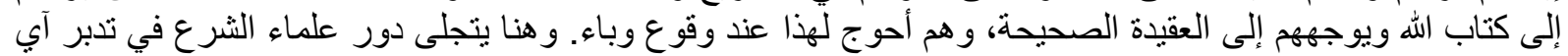

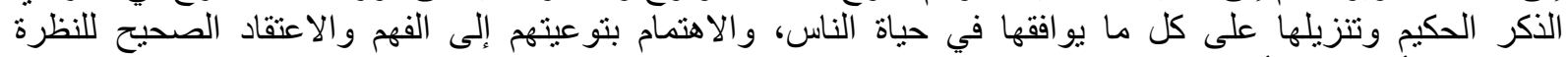

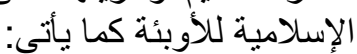

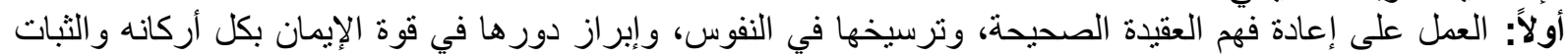

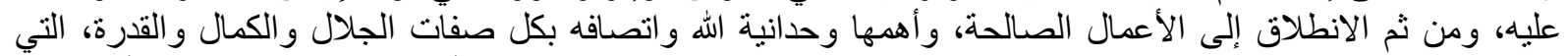

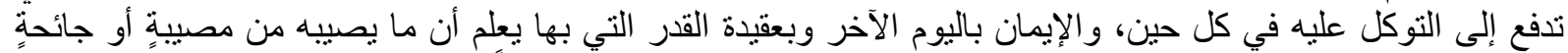

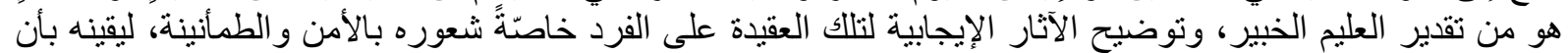

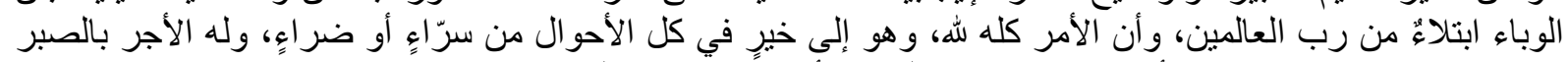

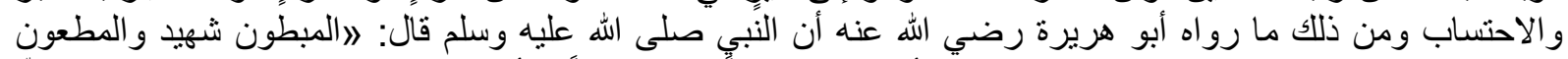

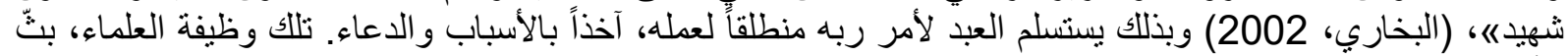

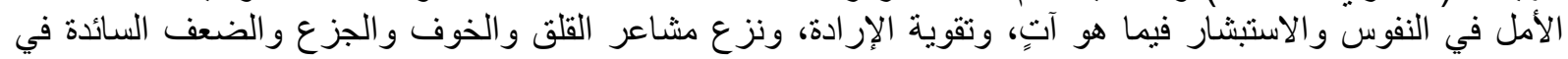

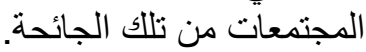

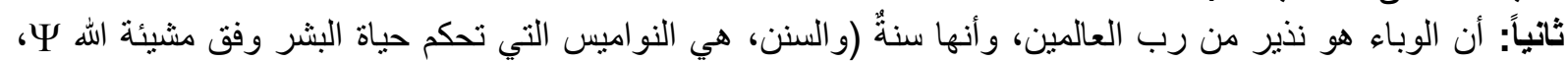

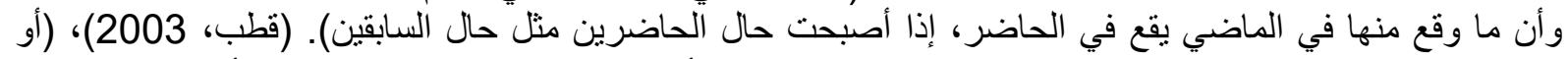

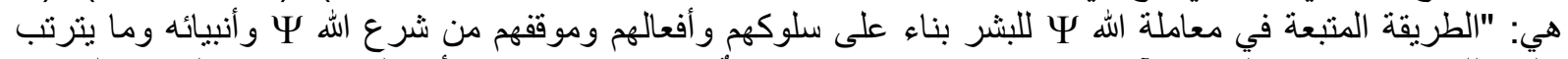

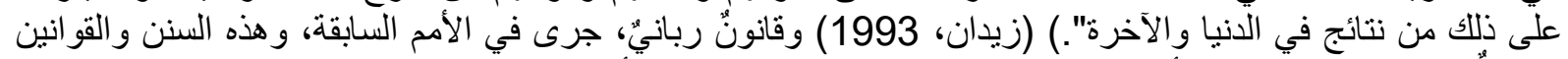

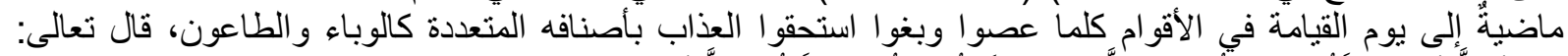

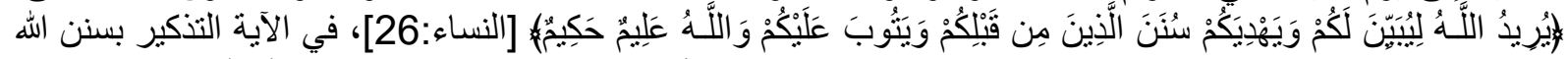

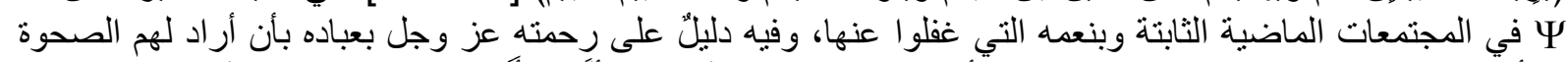

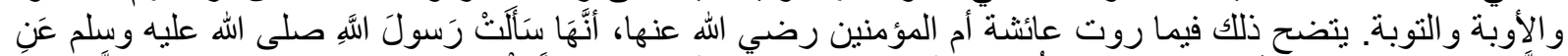

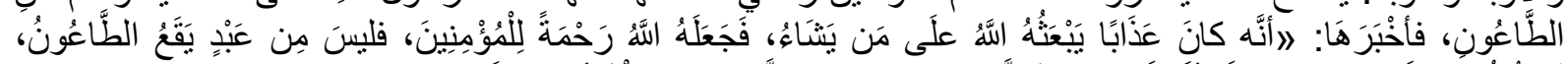

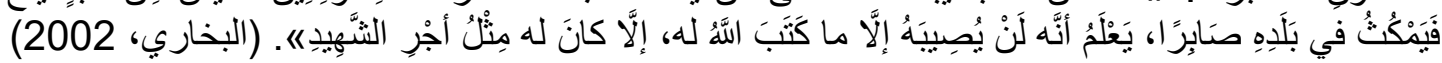




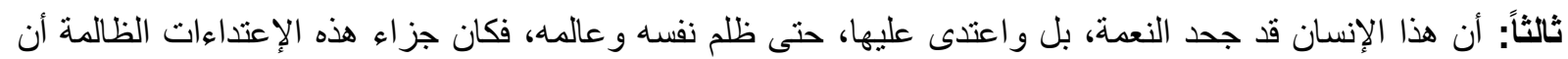

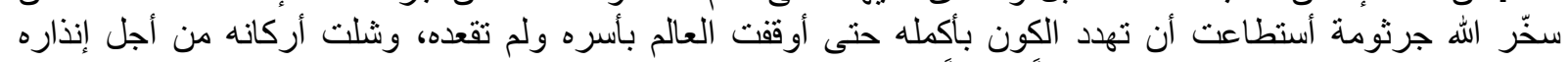

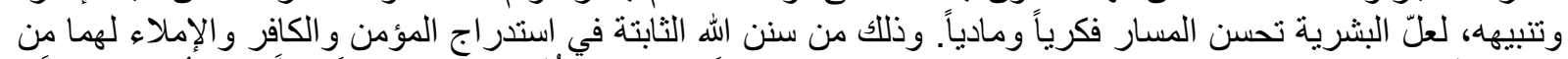

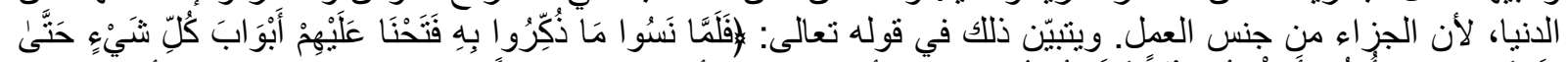

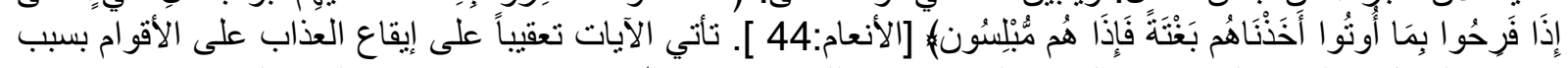

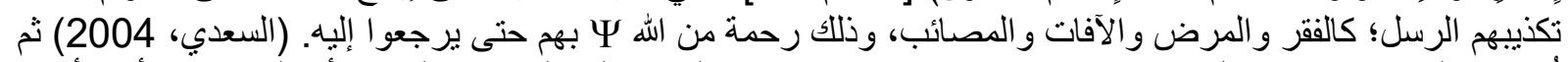

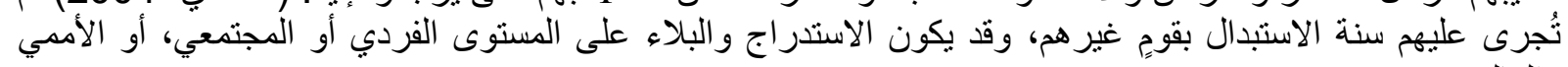

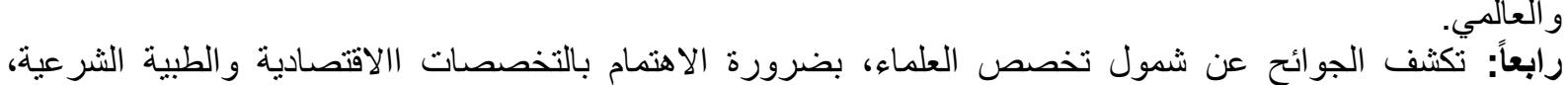

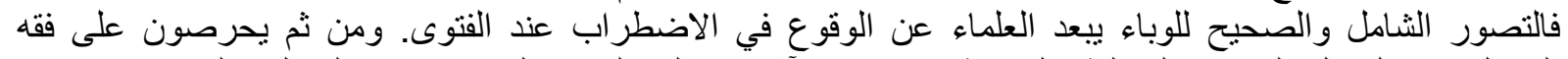

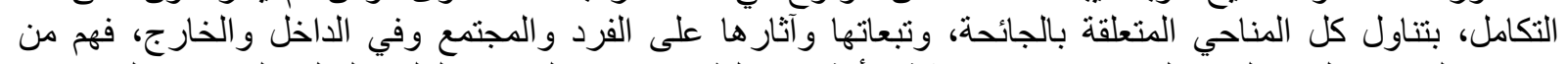

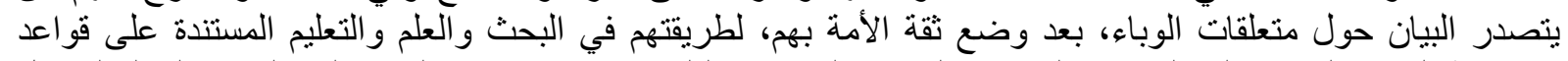

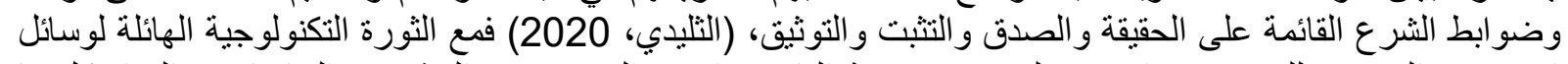

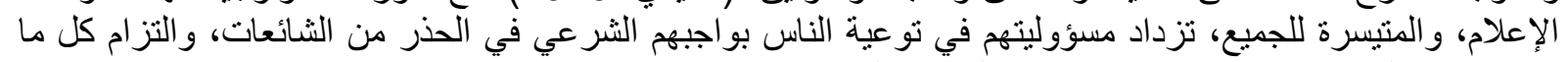

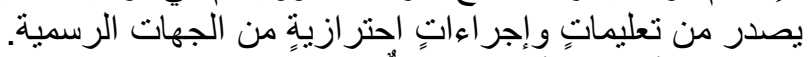

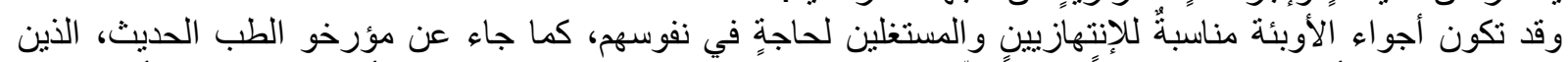

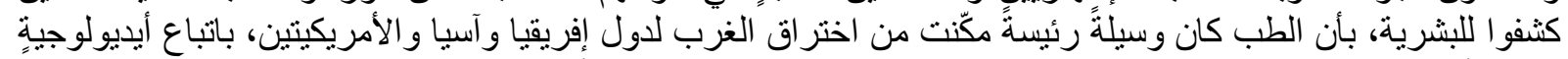

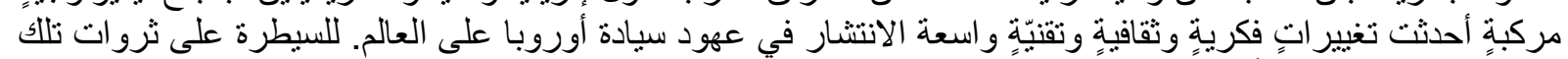

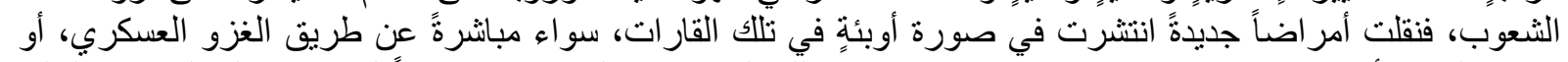

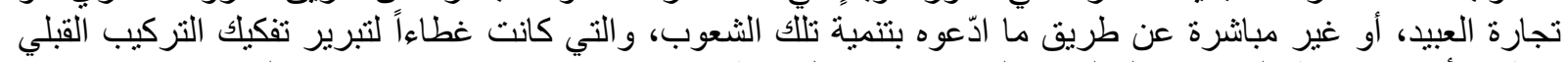

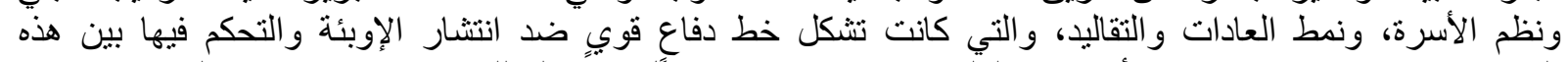

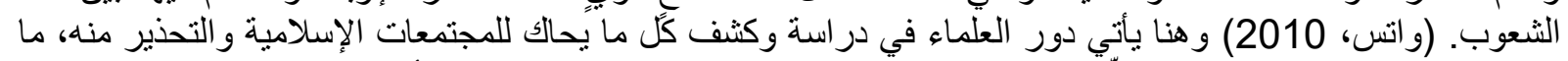

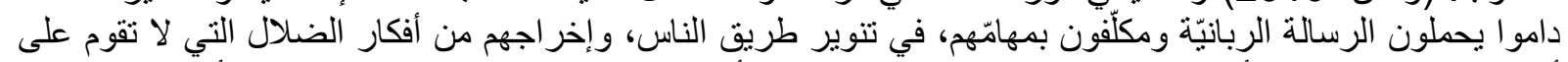

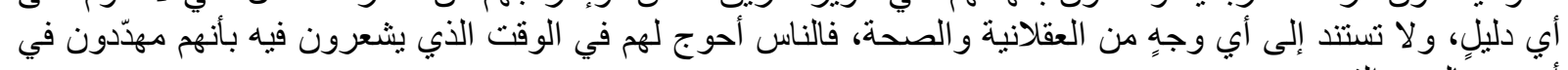

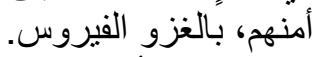

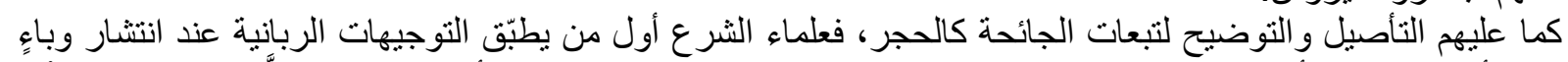

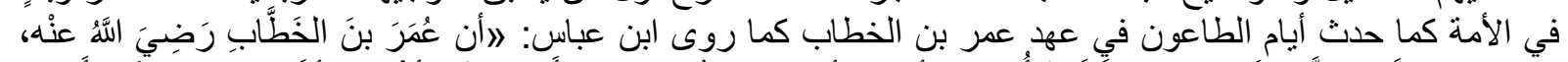

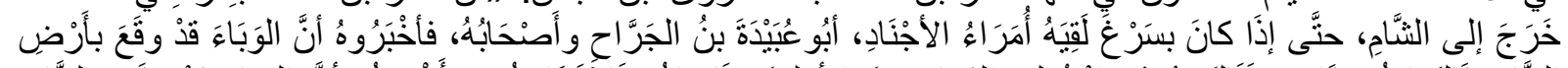

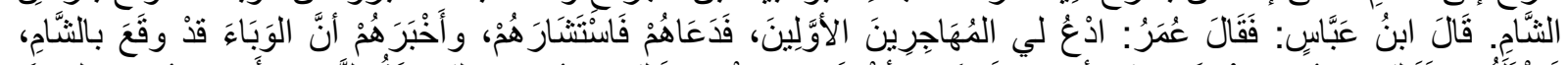

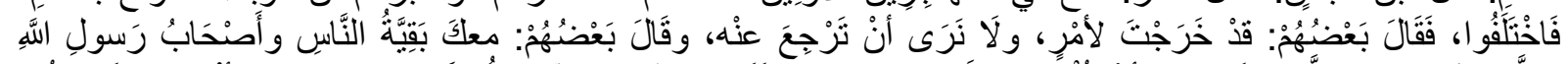

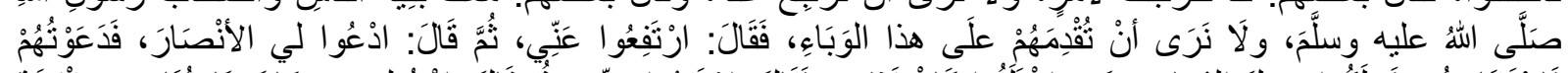

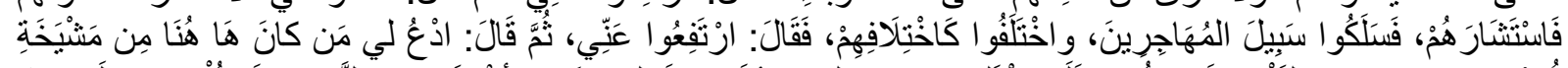

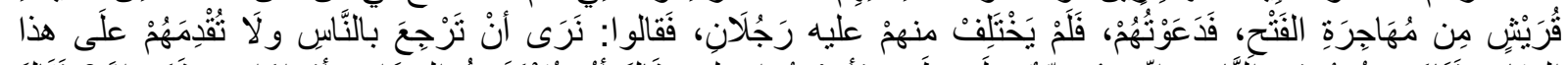

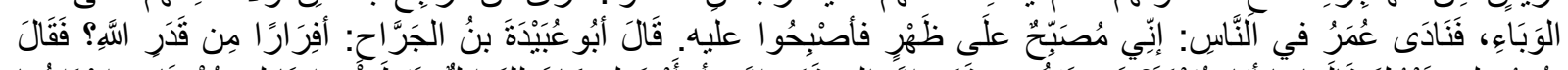

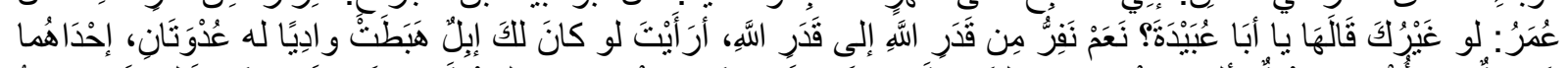

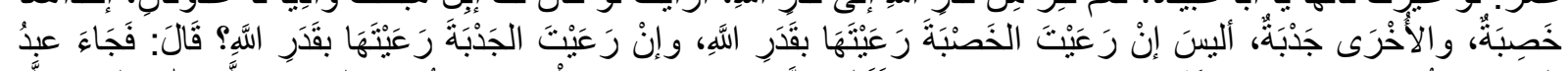

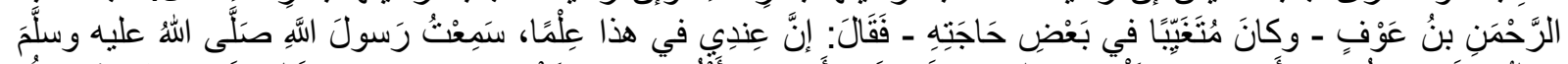

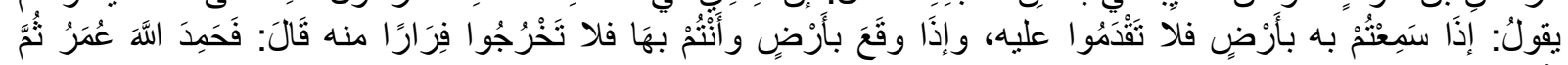

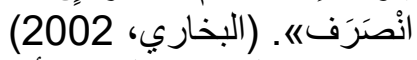

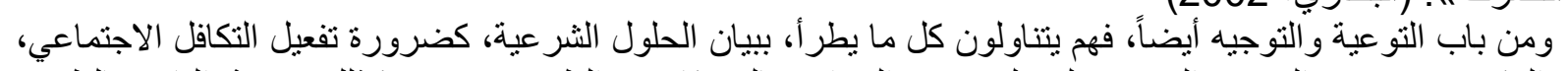

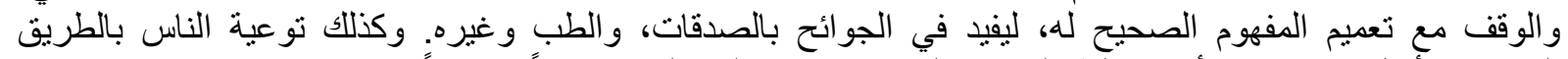

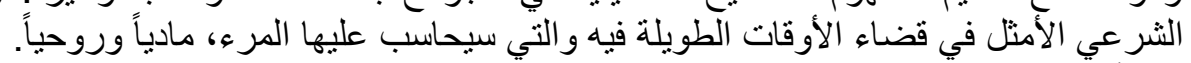

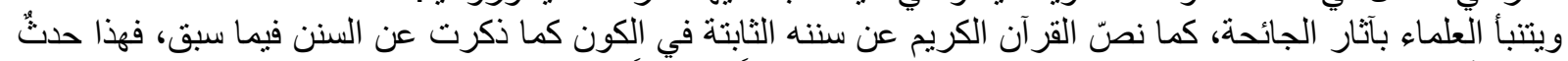

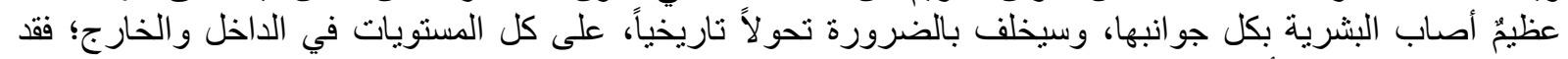

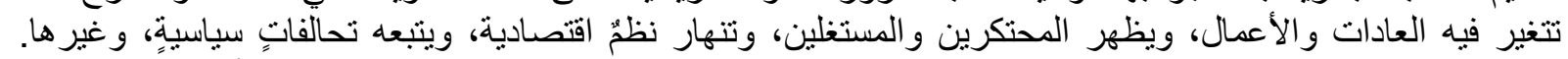

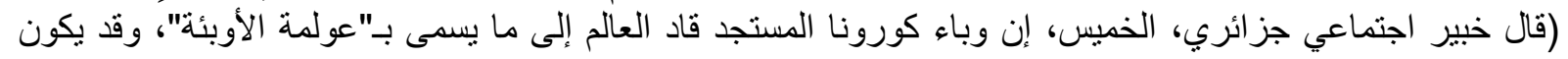


سبيا لتغيرات جذرية بالنظام الدولي وقيم المجتمعات. جاء ذلك في محاضرة للأستاذ في كلية الآداب و العلوم الإنسانية

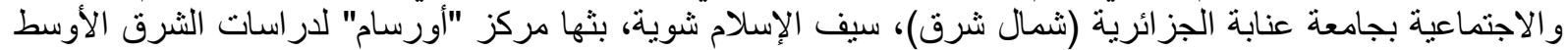

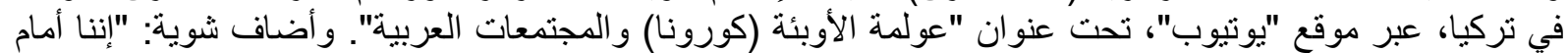

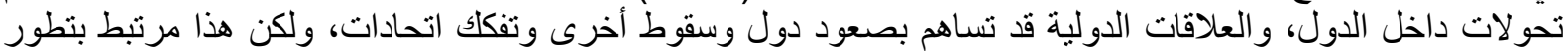

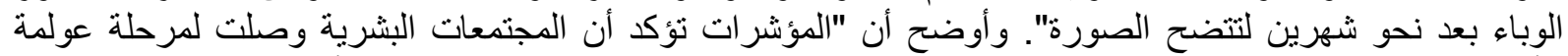

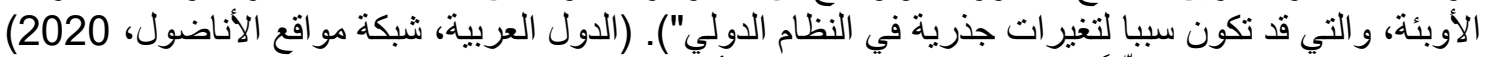

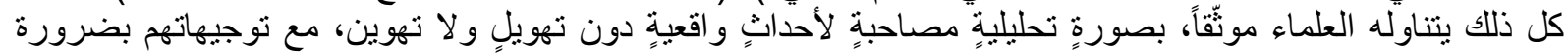

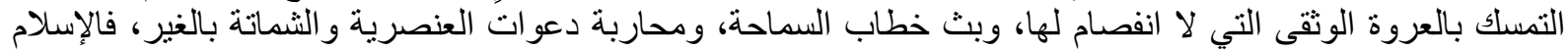

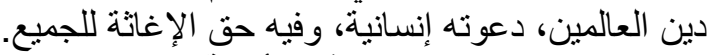

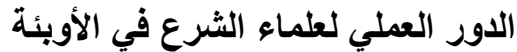

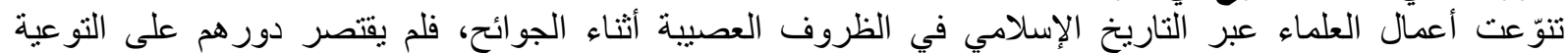

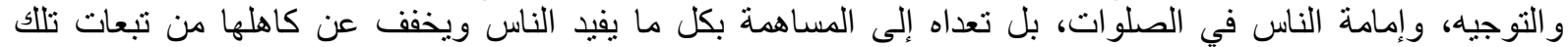

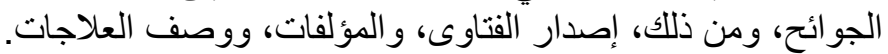

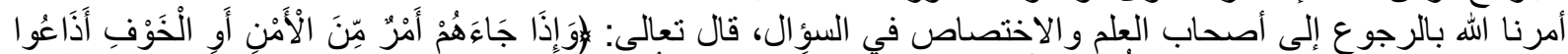

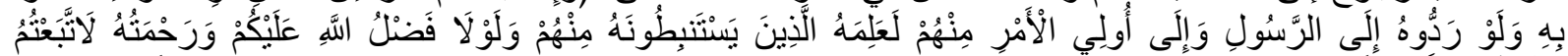

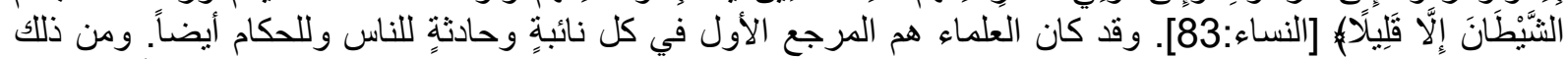

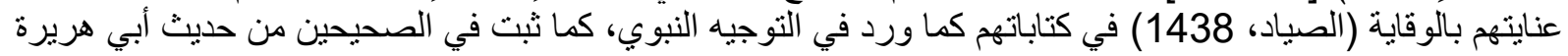

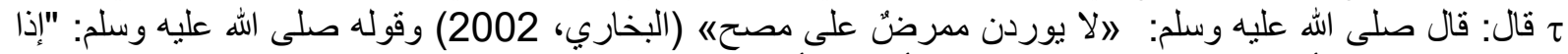

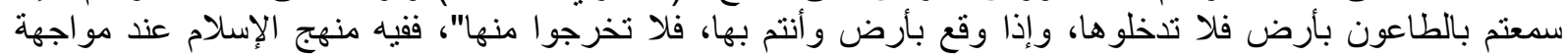

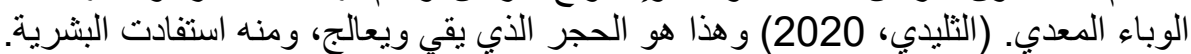

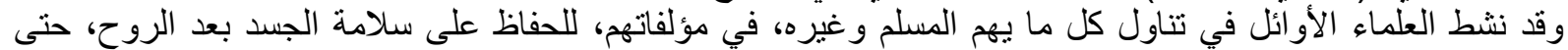

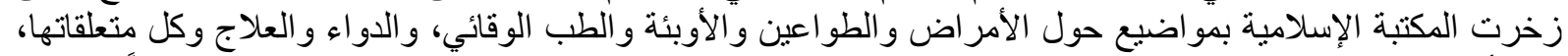

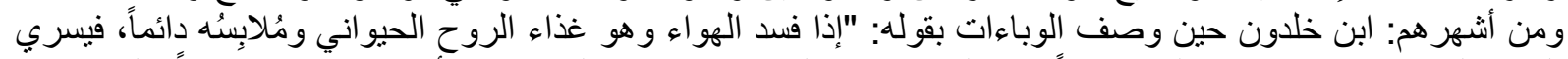

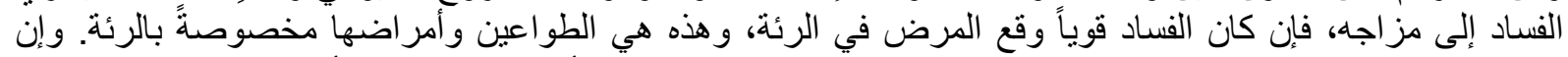

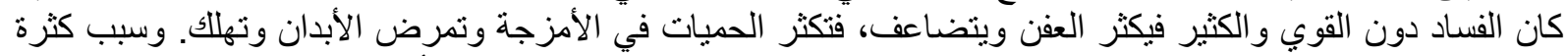

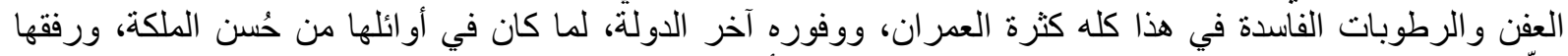

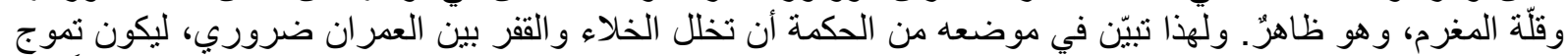

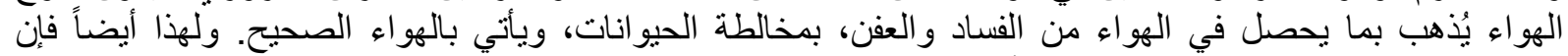

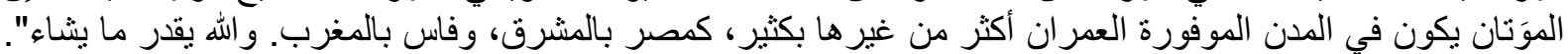

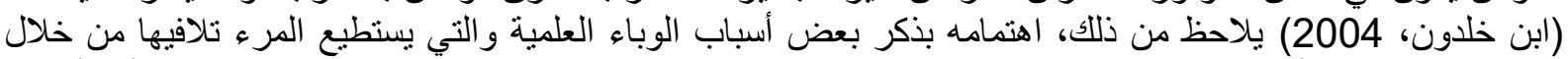

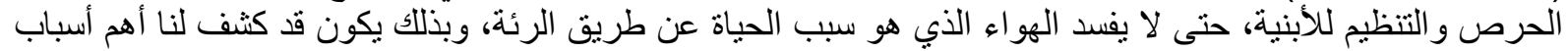
الوباء، وبالتالي يسنطيع الأطباء الارتقاء في علاجهم من خلال ذلاء. (فيروس كورونا الذي انتشر في هذا الزمان من عن عام

(2020

وهذا ابن القيّم ينصح بعلاج روحي بقوله عن الأوبئة: "لا يدفعها دافعٌ أقوى من هذه الأسباب من الذكر و الدعاء، و الابتهال

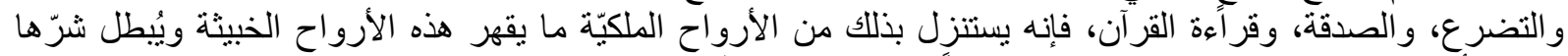

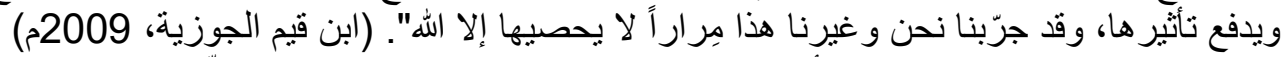

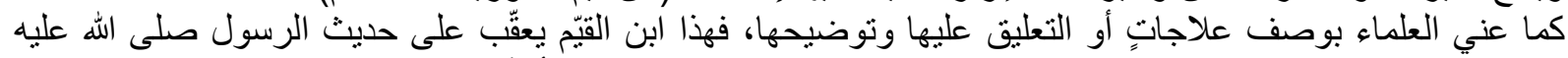

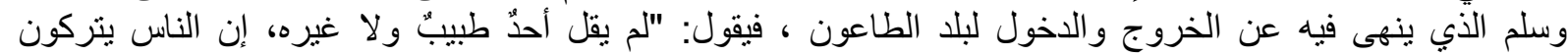

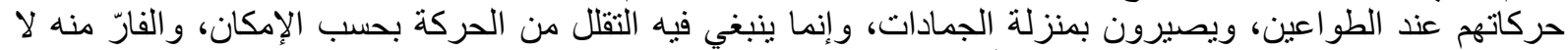

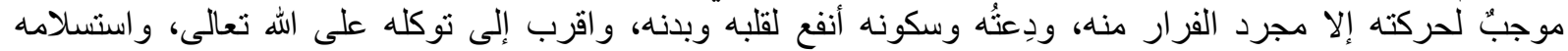

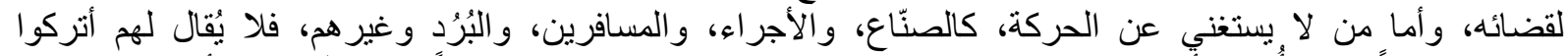

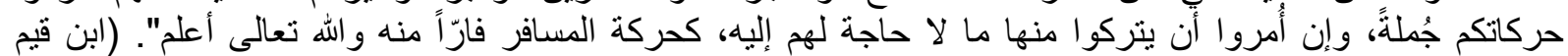

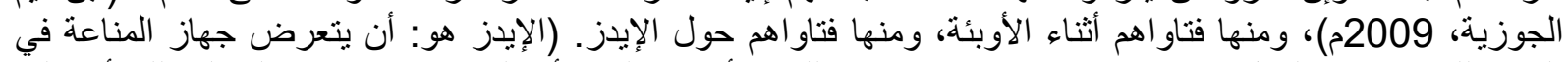

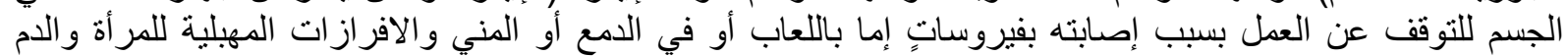

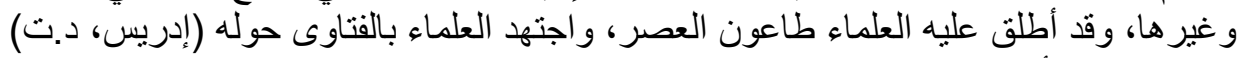

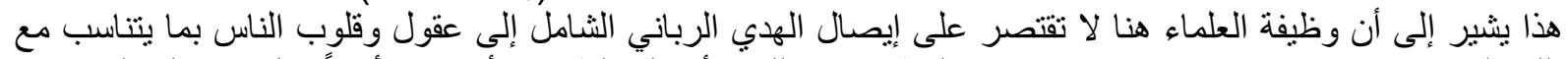

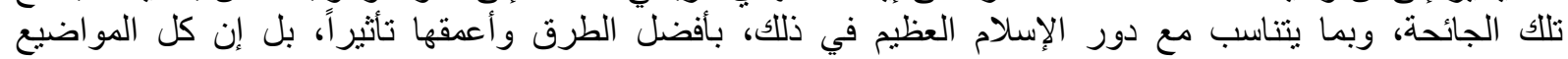
و المستويات التي يطرقونها لها دور ها في تحقيق الصحة المعنوية والجسدية. 


\section{كدى الاور الريادي لطماء الثرع في جائحة كورونا}

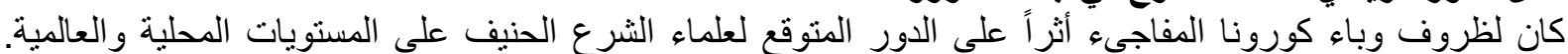

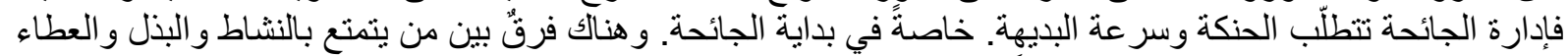

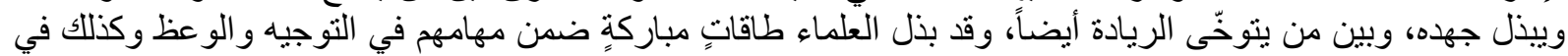

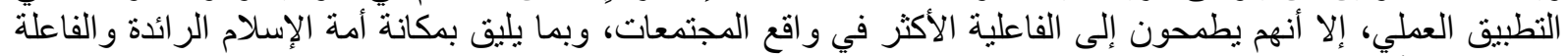

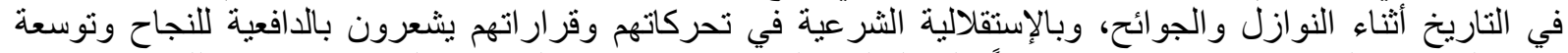

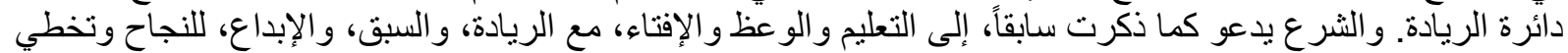

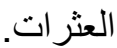

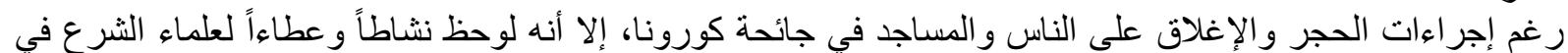

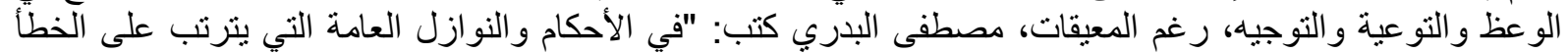

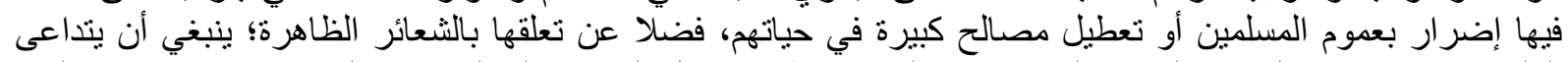

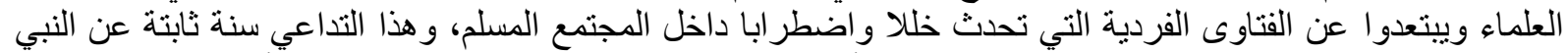

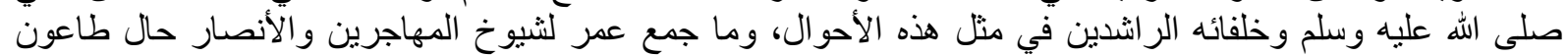

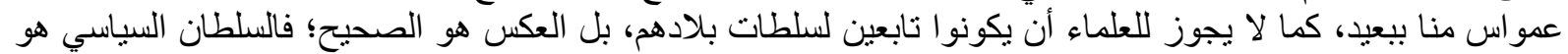

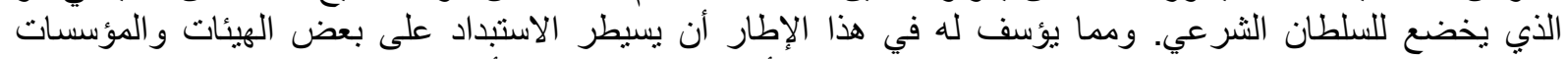

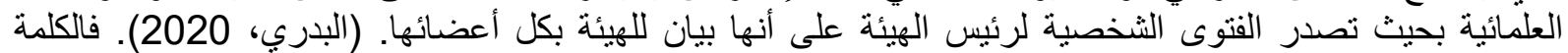

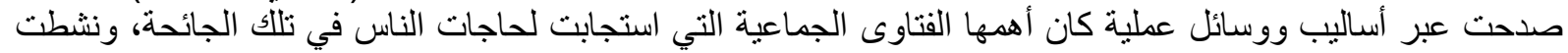

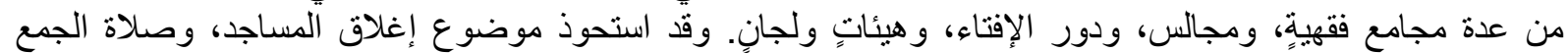

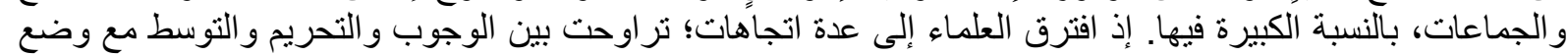

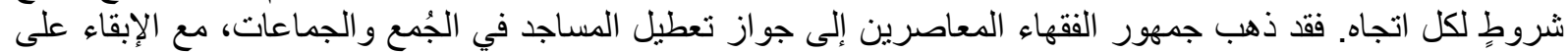

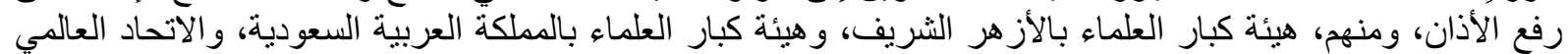

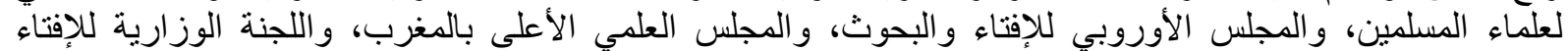

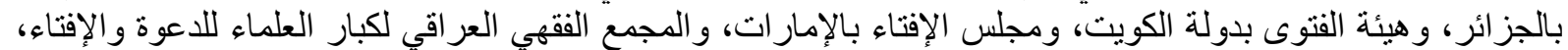

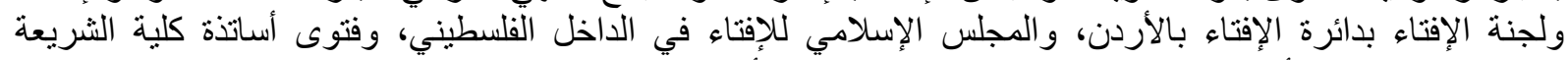

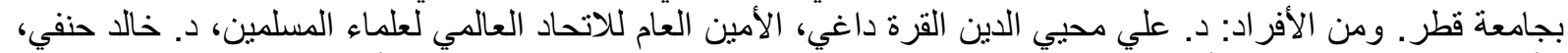

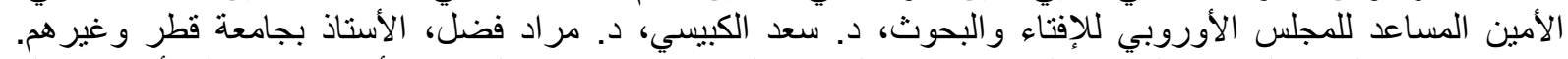

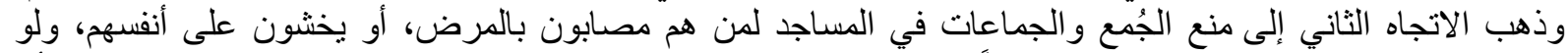

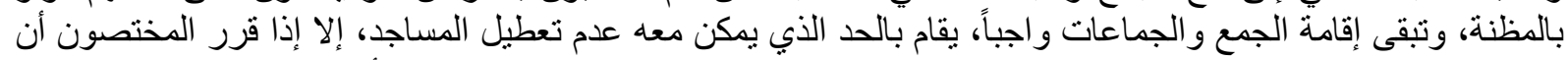

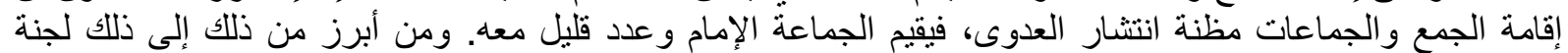

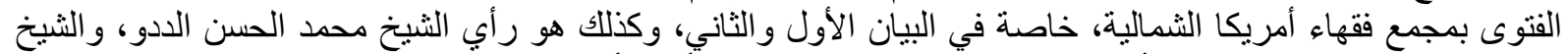

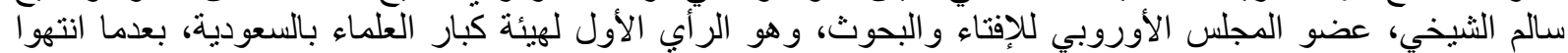

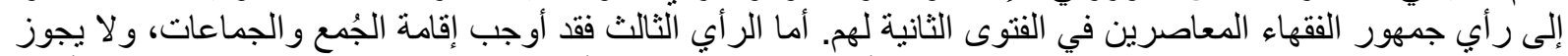

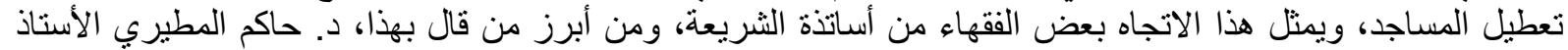

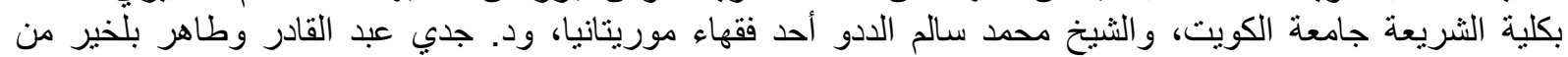

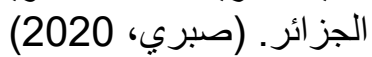
و هناكلكا الكثير من الموبراضيع اللازمة في الجائحة كما بتضح في الصورة الآتية والتي تتضمن نماذج للفتاوى وأماكن

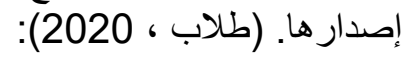




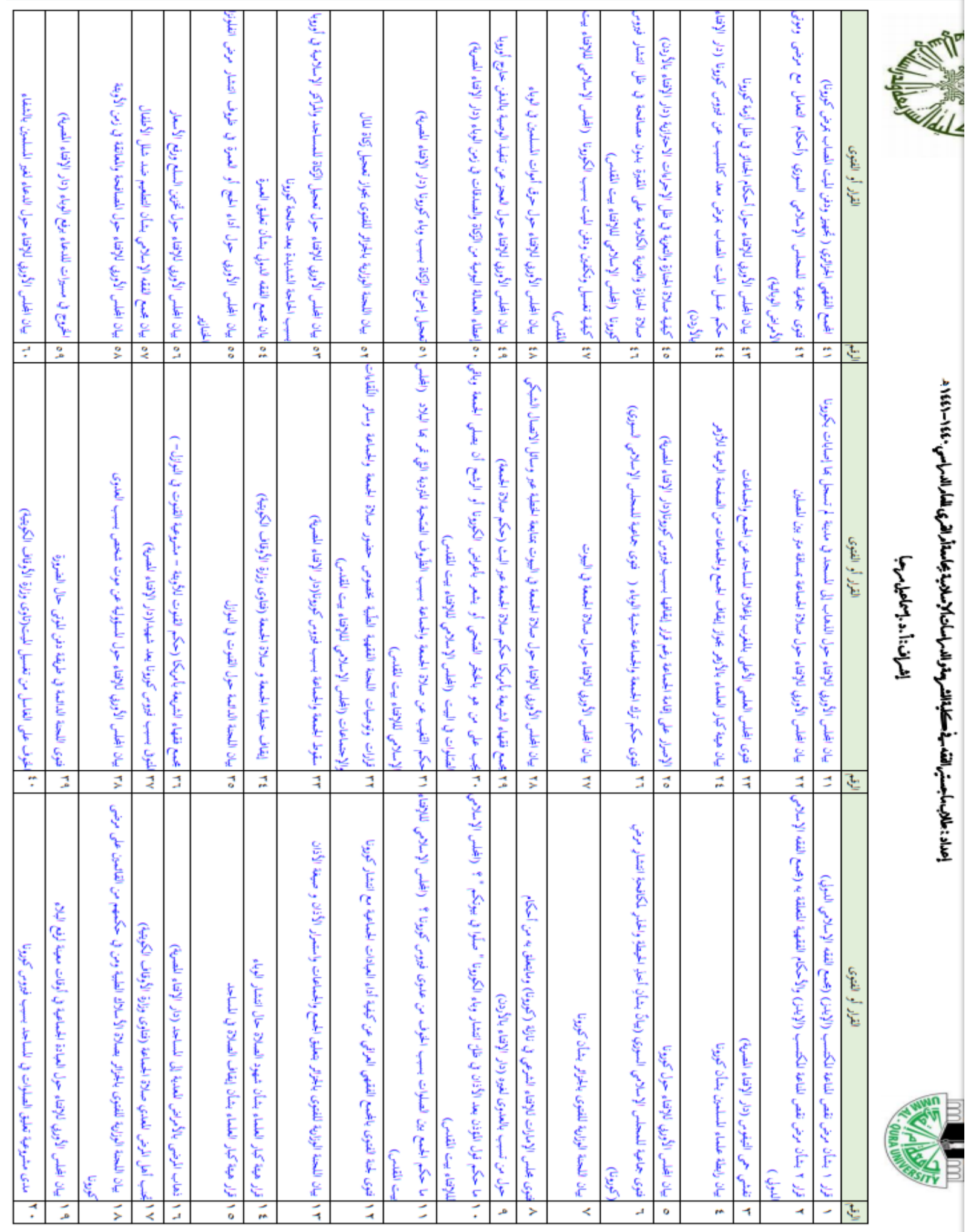




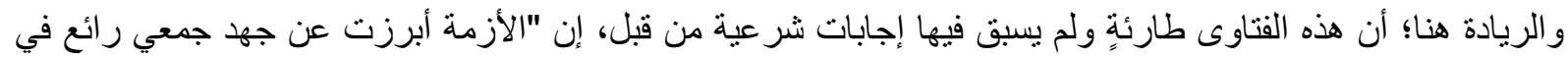

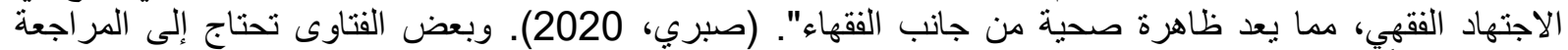

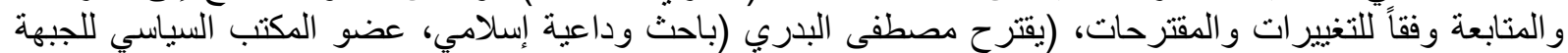

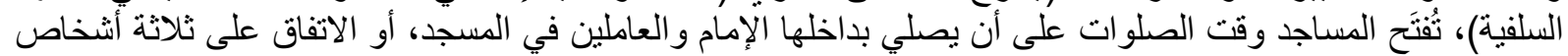

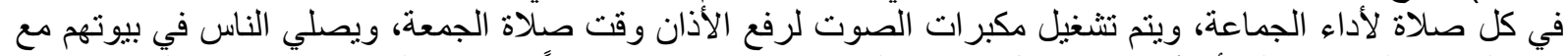

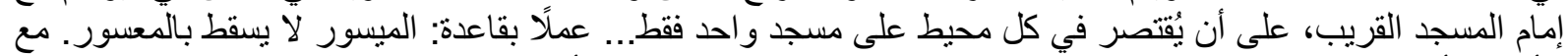

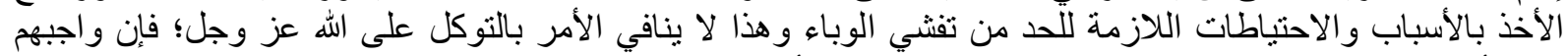

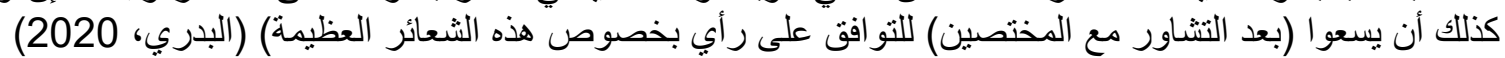

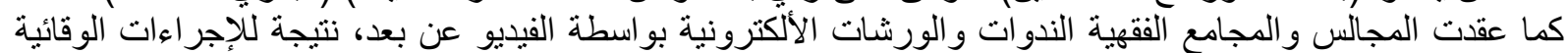

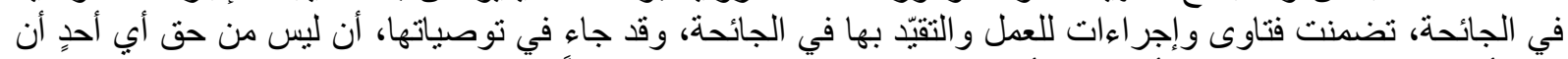

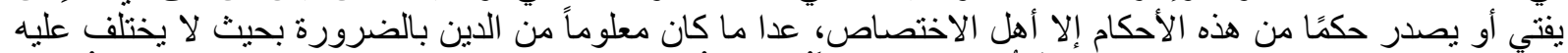

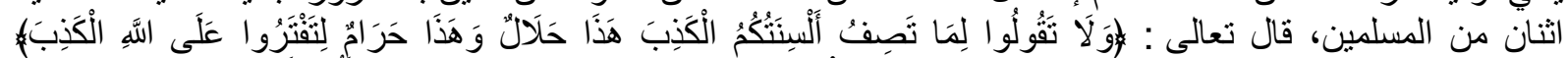

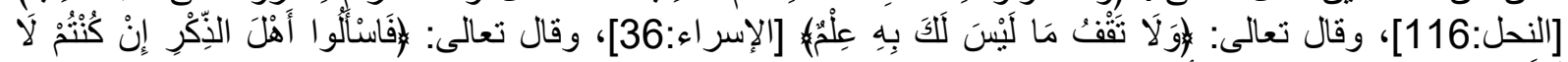

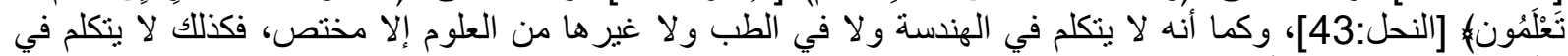

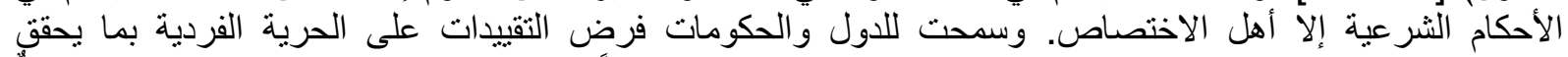

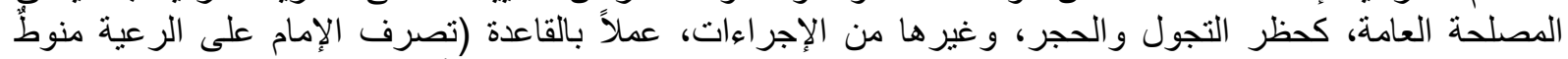

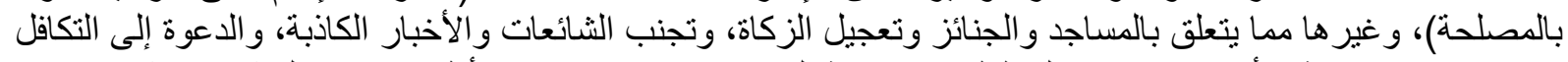

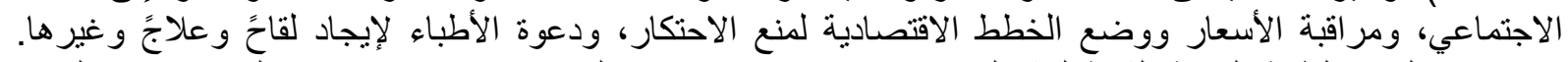

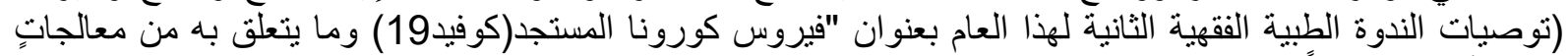

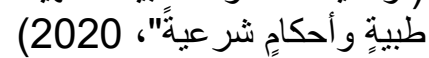

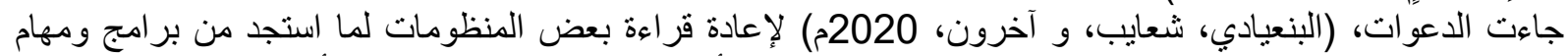

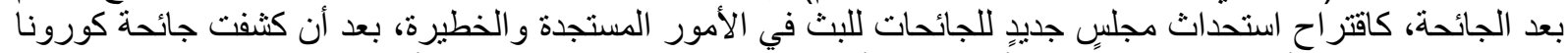

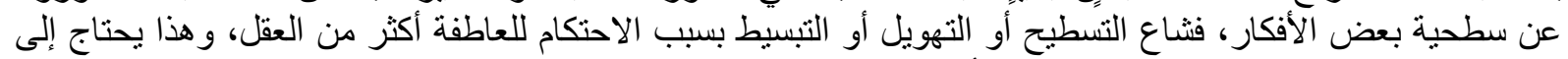

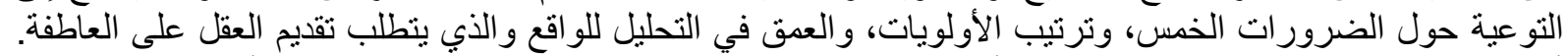

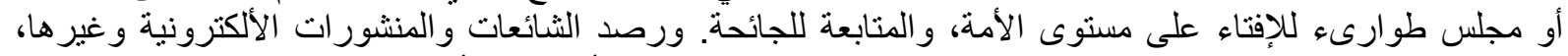

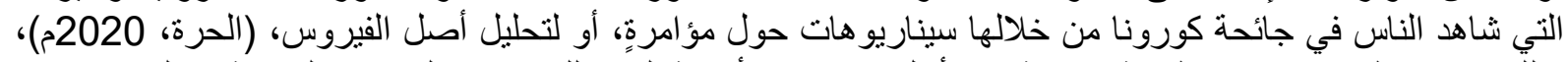

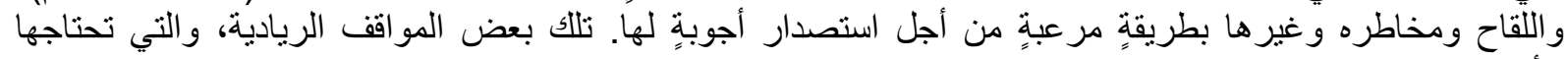

استبانةٌ حول مدى ريادة علماء الثرع في جائحة كورونـا وبعض الآراء

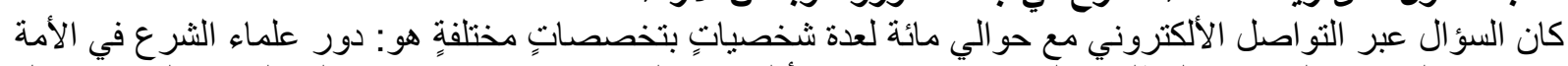

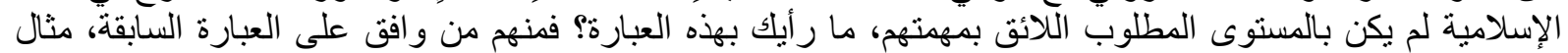

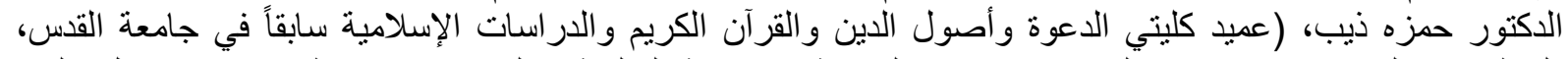

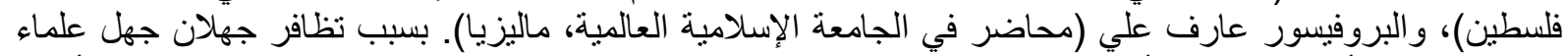

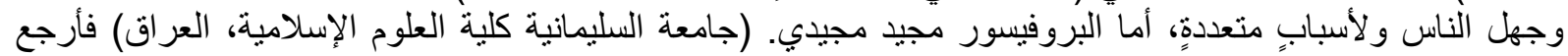

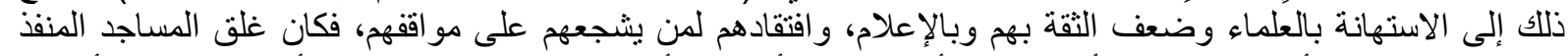

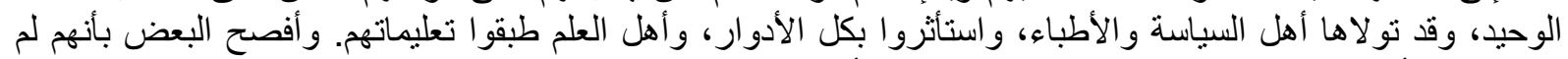

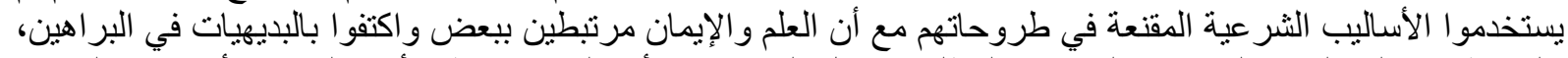

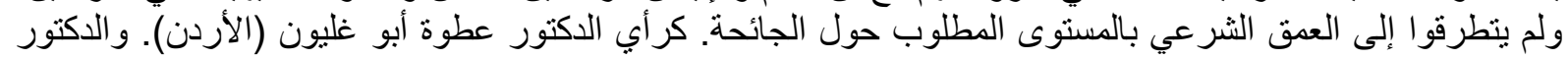

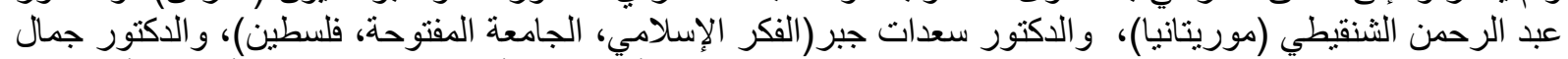

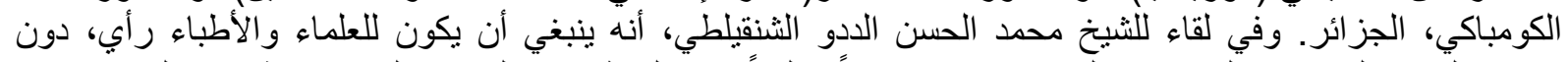

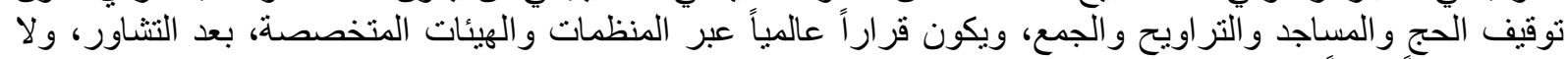

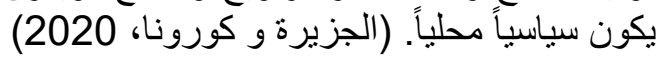

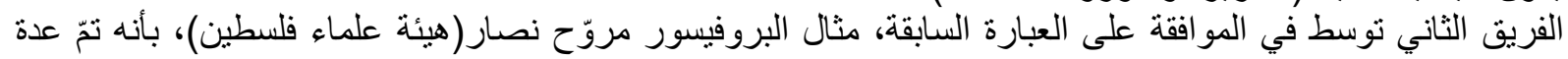

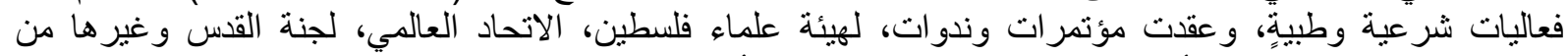

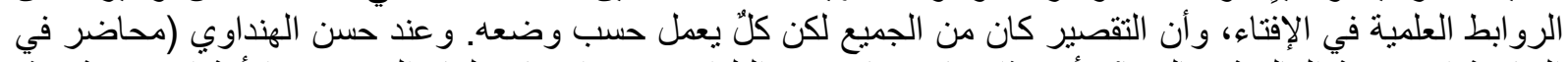

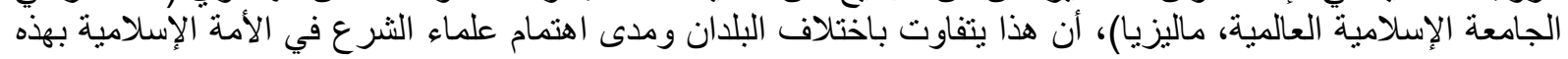


الجائحة، ولم يكن بالمستوى الذي يليق بعلماء الأمة، ذللك يرجع إلى عدم الوعي بمقصد الأمن الصحي في المجتمع، و أنه

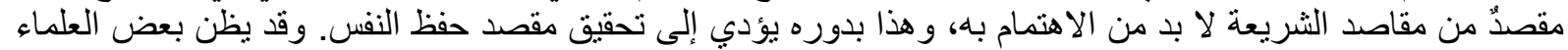

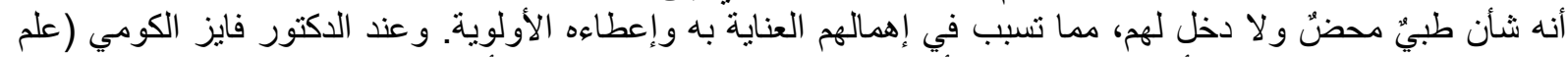

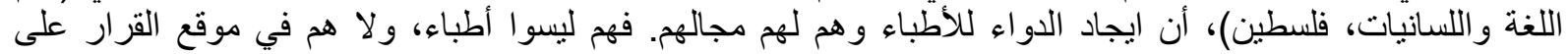

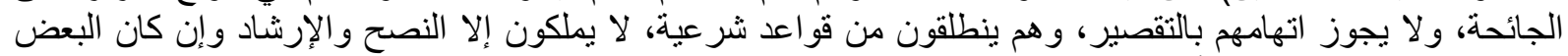

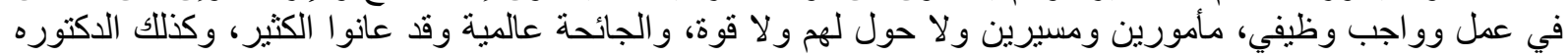
بيأن الطنطاوي (ماليزيا).

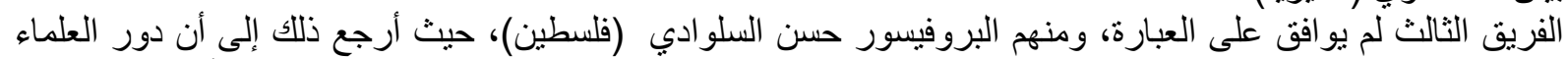

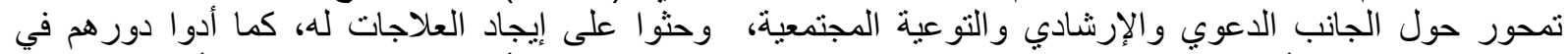

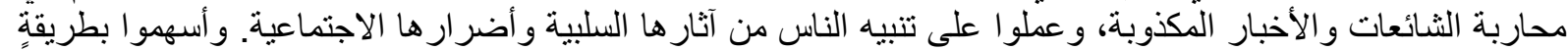

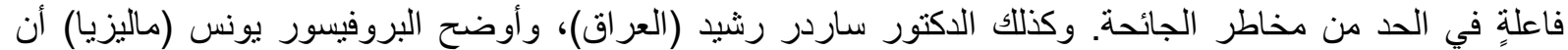

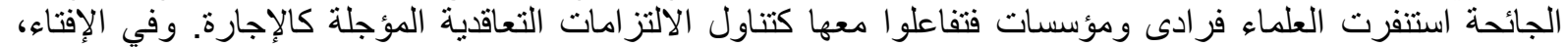

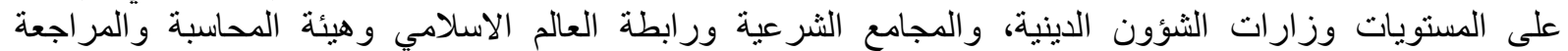

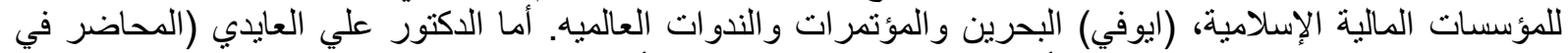

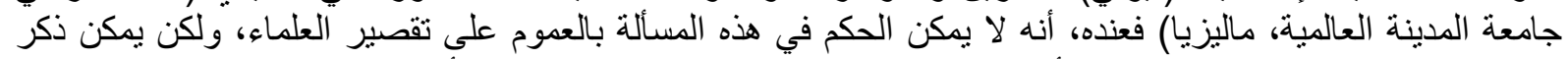

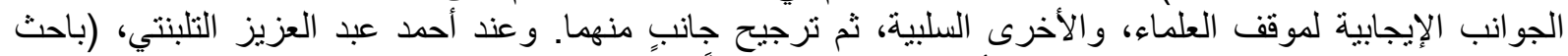

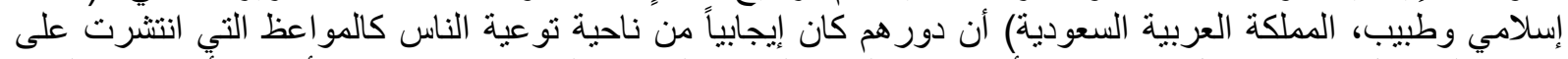

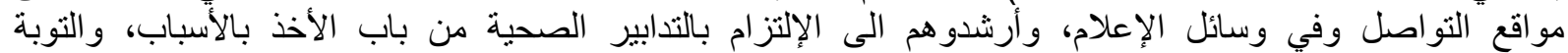

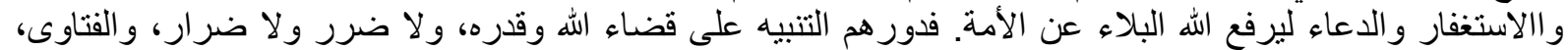

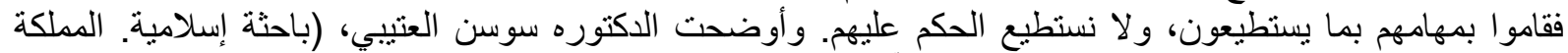

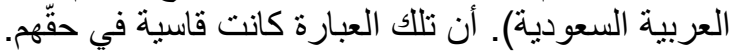
خلاصة ذلك الاستبيان يظهر تأرجح الأراء، ممأ يعني حاجة الأمة إلى الريادية لعلماء الثرع مع أن التفاعل قد حصل

منهم.

خاتمة وتوصيات

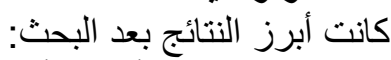

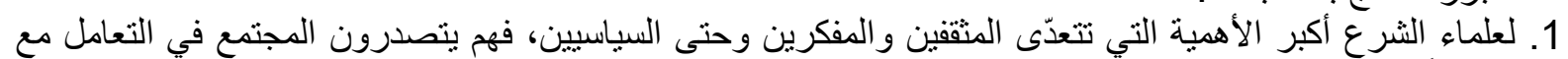

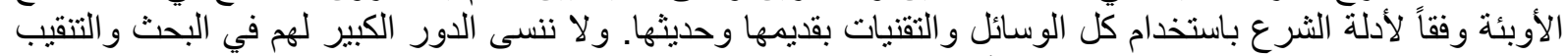

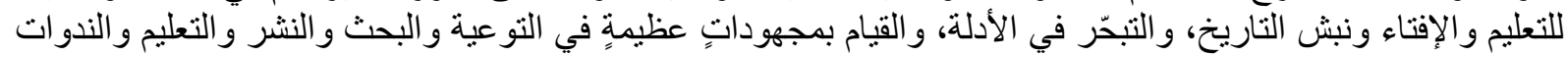

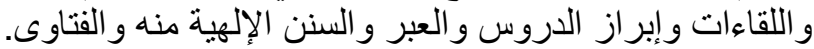

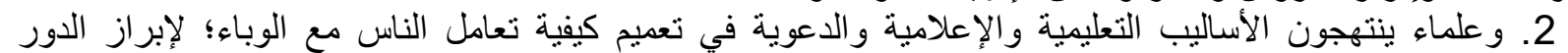

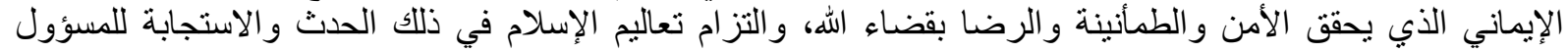

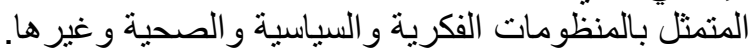

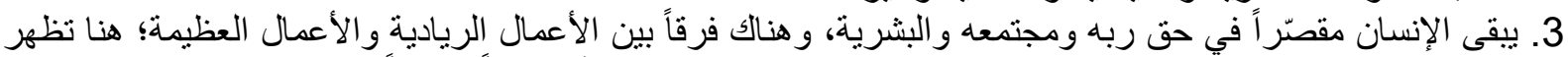

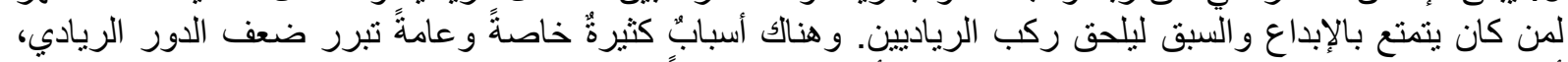

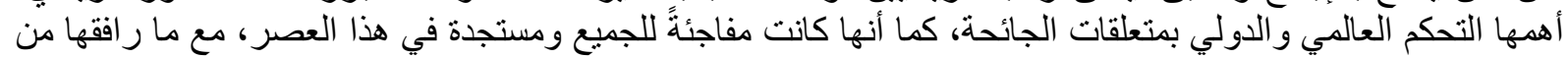

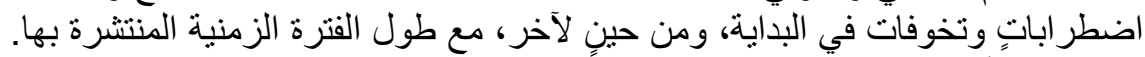

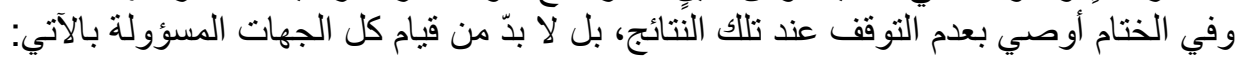

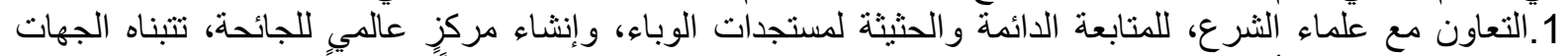

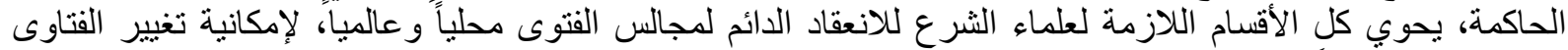

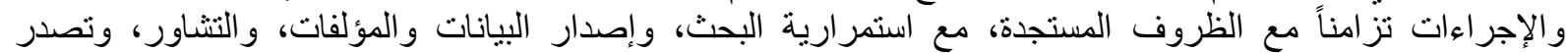

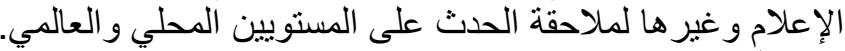

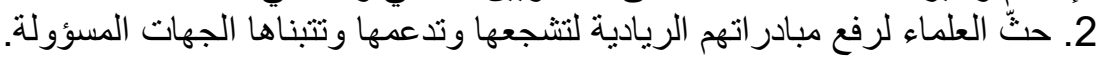




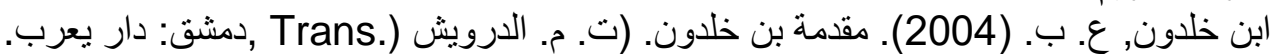

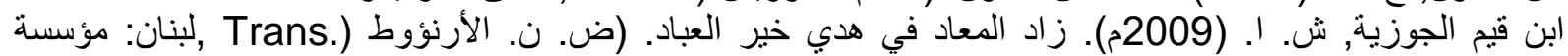
الر الرسالة.

أبو داود سليمان بن الأشعث السجستاني. (2009). سنن أبي داود (الإصدار كتاب العلم، باب الحث على طلى طلب العلم،

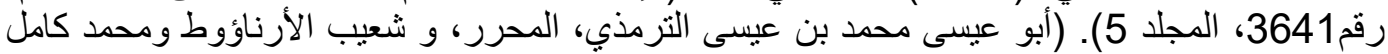

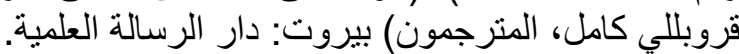

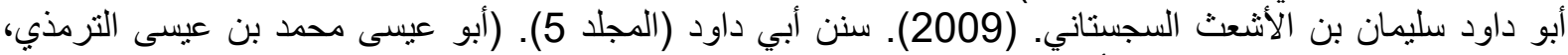

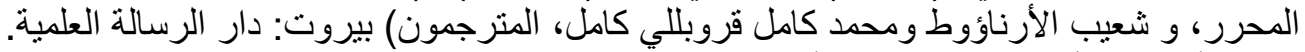

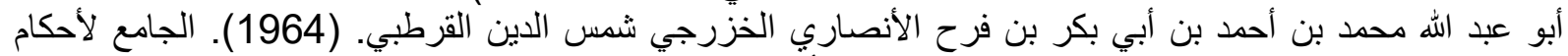

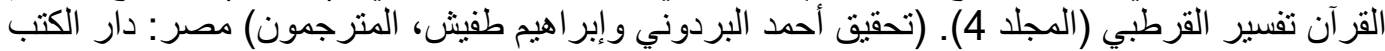

المصرية.

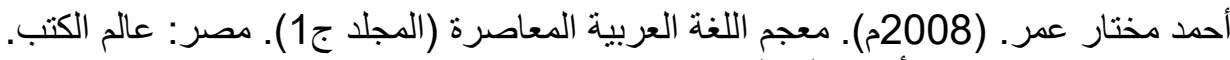

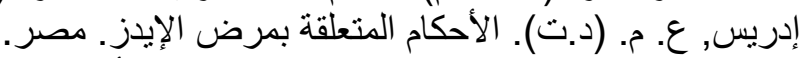

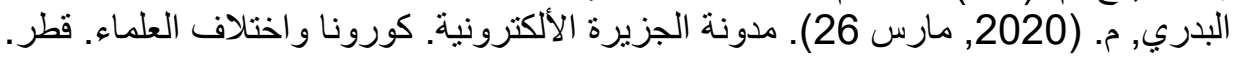

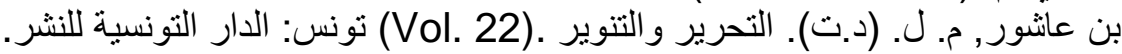

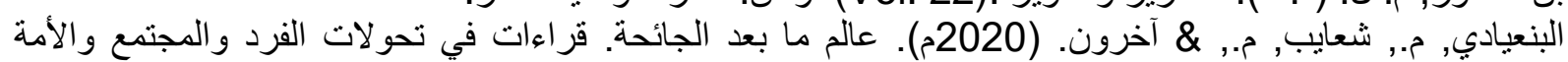

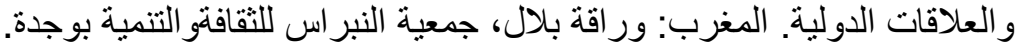

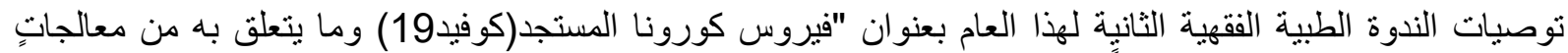

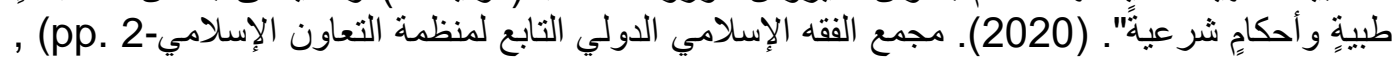
(11).

الثليدي, أ. (2020, مارس 13). مجلة عربي 21. العلماء في مواجهة كورونا..أب مساهمة الدين في تجنب الوباء. الرباط.

الجزيرة, \& كورونا, ب. أ. (2020, جلاي 23) 2020. لقاء قناة الجزيرة، قطر.

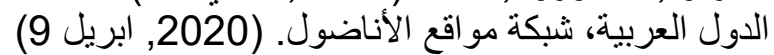

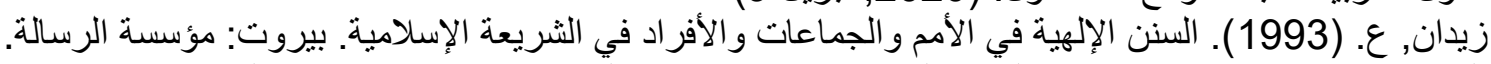

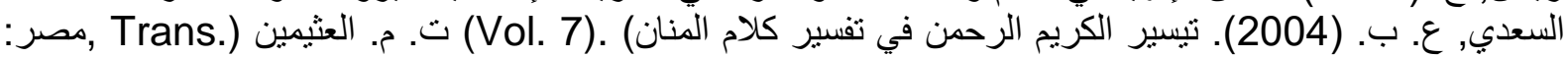
مكتبة الصفا.

سيد إبر اهيم الثاذلي قطب. (2003). في ظلال القرآن (المجلد 4). مصر: دار الثرانة الثروق.

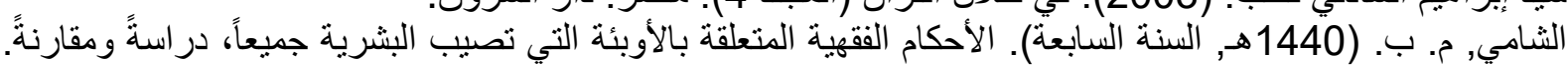
جامعة طيبة للآداب و العلوم الإنسانية.

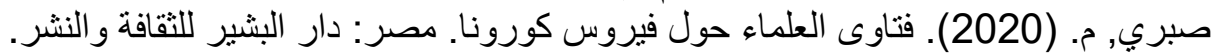

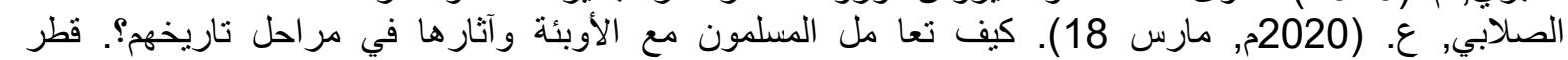
الجزيرة.

طلاب , م. ا. (2020). القرارات والفتاوى الجماعية حول الأمراض المعدية. (إ. الـ مرجا (. Trans المعلكة العربية

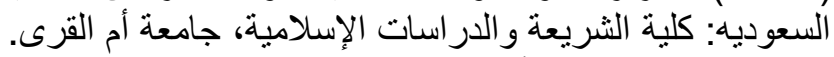

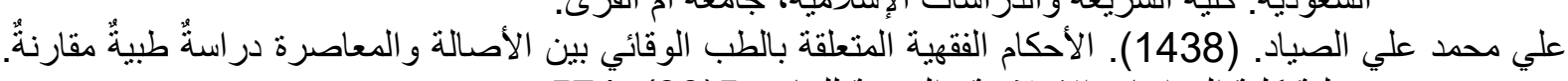

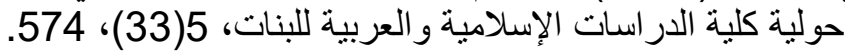

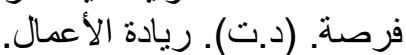

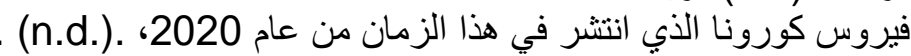

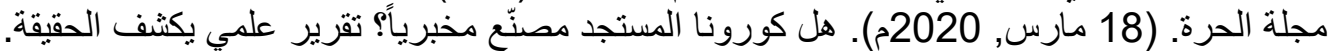

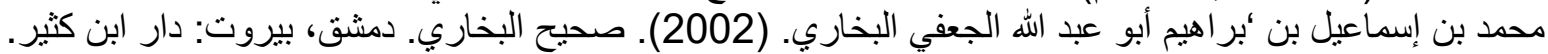

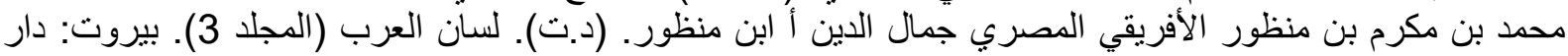
صنادر. 


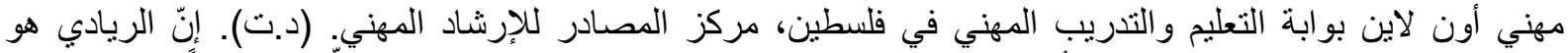

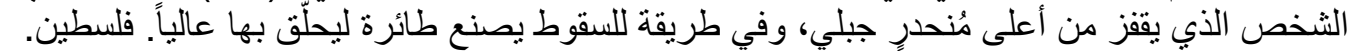

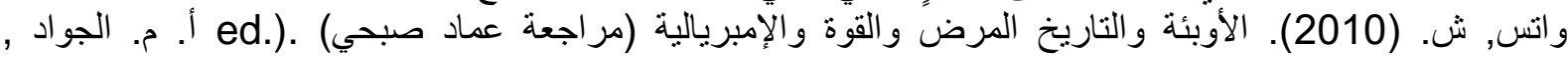
(2020). (مصر: المركز القومي للترجمة. (2010)

يونيسيف لكل طفل. (2020). ما هو فيروس كورونا المستجد. فلسطين. 